OPTION-IMPLIED PREFERENCES

ADJUSTMENTS, DENSITY

FORECASTS, AND THE EQUITY

RISK PREMIUM

Erancisco Alonso, Roberto Blanco.

and gonzalo Rubio

Documentos de Trabajo.

N. 0630

baneo españa

2006

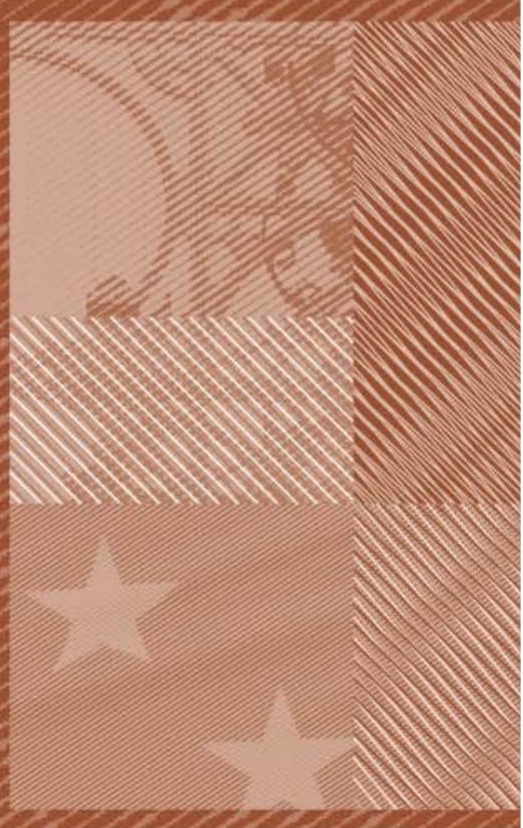


OPTION-IMPLIED PREFERENCES ADJUSTMENTS, DENSITY FORECASTS, AND THE EQUITY RISK PREMIUM 


\title{
OPTION-IMPLIED PREFERENCES ADJUSTMENTS, \\ DENSITY FORECASTS, AND THE EQUITY RISK PREMIUM $\left(^{*}\right)$
}

\author{
Francisco Alonso and Roberto Blanco $\left(^{\star \star}\right)$ \\ BANCO DE ESPAÑA
}

Gonzalo Rubio (**)

UNIVERSIDAD DEL PAÍS VASCO AND UNIVERSITAT POMPEU FABRA

\begin{abstract}
(*) We thank Juan Ayuso, Manuel Moreno, Belén Nieto, Fernando Restoy, Peng Yu, the anonymous referee of the working paper series of the Banco de España and to seminar participants at the Banco de España, XIII Foro de Finanzas and the 2006 Annual Conference of the European Financial Management Association for helpful comments. The contents of this paper are the sole responsibility of the authors.

(*) Francisco Alonso (falonso@bde.es); Roberto Blanco (rblanco@bde.es); Gonzalo Rubio (gonzalo.rubio@ehu.es, gonzalo.rubio@upf.edu).
\end{abstract}


The Working Paper Series seeks to disseminate original research in economics and finance. All papers have been anonymously refereed. By publishing these papers, the Banco de España aims to contribute to economic analysis and, in particular, to knowledge of the Spanish economy and its international environment.

The opinions and analyses in the Working Paper Series are the responsibility of the authors and, therefore, do not necessarily coincide with those of the Banco de España or the Eurosystem.

The Banco de España disseminates its main reports and most of its publications via the INTERNET at the following website: http://www.bde.es.

Reproduction for educational and non-commercial purposes is permitted provided that the source is acknowledged.

\section{(c) BANCO DE ESPAÑA, Madrid, 2006}

ISSN: 0213-2710 (print)

ISSN: 1579-8666 (on line)

Depósito legal: M.49724-2006

Imprenta del Banco de España 


\begin{abstract}
The main objective of this paper is to analyse the value of information contained in prices of options on the IBEX 35 index at the Spanish Stock Exchange Market. The forward looking information is extracted using implied risk-neutral density functions estimated by a mixture of two-lognormals and several alternative risk-adjustments: the power, exponential and habit-inspired based stochastic discount factors. Moreover, by allowing additional flexibility in the shape of the stochastic discount factor, two other ad hoc time-varying risk aversion adjustments are also employed. Our results show that, between October 1996 and March 2000, we can reject the hypothesis that the risk-neutral densities provide accurate predictions of the distributions of future realisations of the IBEX 35 index at four- and eight-week horizons. When forecasting through risk-adjusted densities the performance of this period is statistically improved and we no longer reject that hypothesis. Somehow surprisingly, all risk-adjusted densities generate similar forecasting statistics. Finally, from October 1996 to December 2004, the ex-ante risk premium perceived by investors and that are embedded in option prices is between 12 and 18 percent higher than the premium required to compensate the same investors for the realised volatility in stock market returns.
\end{abstract}

JEL: G10, G12.

Keywords: risk-adjustments, option-implied densities, forecasting performance, equity-risk premium. 


\section{Introduction}

Prices of European exchange-traded options on stock indices implicitly contain the risk-neutral density (RND hereafter) which is a key component for risk-neutral valuation. In this context, prices are the present value at the risk-free rate of their expected payoffs calculated under the RND. When the market is dynamically complete it is well known that a RND valid for pricing all assets can be recovered from the corresponding option prices using the insights on Breeden and Litzenberger (1978). In particular, the RND is proportional to the second derivative of the option pricing function with respect to the exercise.

Noting that option prices should capture forward-looking distributions of the underlying assets, academic researchers and central banks have used implied RNDs to proxy the market expectations of the distribution of the underlying asset or to forecast future outcomes. They have the advantage relative to other historical time-series data that they are taken from a single point in time when looking toward expiration. Hence, they should be more responsive to changing expectations than competing alternatives. Unfortunately, in practice, there is no a continuum of exercise prices. Neither very low nor high exercises are available and, in any case, they are set at discrete intervals by market officials. This complicates the estimation of RND and, not surprisingly, numerous alternative parametric and non-parametric methods have been proposed in literature. Moreover, the existence of risk aversion means that RNDs will probably differ from the actual density from which realizations of returns are drawn.

Interestingly most of the literature is concerned with the estimation and the ex-post assessment of the alternative RNDs as a way of forecasting the actual realizations of the underlying asset at expiration. Bliss and Panigirtzoglou (2002) and Bondarenko (2003) compare several competing procedures and conclude that nonparametric methods base on either the smoothed (spline) implied volatility smile and the positive convolution approximation seem to dominate the two-lognormal approach and other parametric techniques when estimating RNDs. Moreover, Anagnou, Bedendo, Hodges and Tompkins (2005) for the UK option market, Craig, Glatzer, Keller and Scheicher (2003) for the German stock option data, Bliss and Panigirtzoglou (2004) for the US and the UK option data, and Alonso, Blanco and Rubio (2005) for the Spanish option prices conclude that the RND is not an unbiased estimator of actual probability density function. This may not be surprising given the risk-neutrality embedded in these estimates. In other words, these papers suggest that the forecasting differences arise from the risk aversion of the representative investor. In fact, by imposing a stationary utility function (a stationary risk aversion parameter), Bliss and Panigirtzoglou (2004) Anagnou, Bedendo, Hodges and Tompkins (2005), Kang and Kim (2006), and Shackleton, Taylor and Yu (2006) test whether either power or exponential utility adjusted densities are improved forecasters of future values of the underlying. In general, they are not able to reject the null that implied risk-adjusted densities are unbiased forecasts of future outcomes. However, Bliss and Panigirtzoglou obtain a disturbing result in the sense that the implicit risk aversion parameter they estimate increases as market risk declines.

This paper investigates the forecasting power of RNDs for alternative horizons of one, four and eight weeks using exchange data of the European future options contract on the Spanish IBEX-35 index. Given the previous evidence reported by Alonso, Blanco and 
Rubio (2005) in which the predicting ability of RNDs estimated either by a mixture of two log-normals or splines is indistinguishable, we only report results from the parametric log-normal case. Moreover, given the estimation of a RND from a cross-section of option prices with a given maturity, this work obtains the implicit risk adjustment that makes the subjective density forecasts of the agents to be the best assessment of the objective or physical densities from which the realizations are actually drawn. We employ three competing utility functions. As in the previous two existing papers, we assume a constant relative risk aversion power utility function and an exponential utility function, and derive the implicit parameters assuming that their value is stationary over the sample period but using, of course, the time-varying RNDs estimated with our option pricing data. Moreover, given the success of habit preferences in the asset pricing literature and the somehow disturbing findings of Bliss and Panigirtzoglou (2004), we also employ a risk-adjustment inspired in the habit literature. In contrast with more traditional adjustments, habit preferences allow for time-varying risk aversion. Therefore, a risk-adjustment along these lines may potentially help explaining previous results of estimated implied preferences parameters reported in literature. At the same, and with a similar motivation, we also propose two other ad hoc time-varying risk aversion adjustments.

The results of this paper show that between 1996 and 2004 we cannot reject the hypothesis that the RNDs provide accurate predictions of the distributions of future realizations of the IBEX 35 index at one-, four- and eight-week horizons. However, tests based on the tails of the distribution show that RNDs significantly understate the right tail of the distribution at the four-week horizon. Moreover, this predicting ability is not robust by sub-periods. More specifically, and using four- and eight-week horizons, we find that RNDs are not able to consistently predict the realizations of returns from October 1996 to February 2000. These results suggest that the ability of RNDs to forecasts future realizations might possibly be improved if risk preference adjustments were introduced. Indeed, this is the case. Once risk-adjustments are made we are not able to reject the hypothesis that risk-adjusted densities contain good predictions of the distributions of future realizations of the underlying index. Surprisingly, however, all risk-adjusted densities generate similar forecasting statistics. Moreover, for the whole period and contrary to the RNDs, all risk-adjusted densities estimated with our data do not understate the right-tails of the distribution. Interestingly, this latter result is not maintained during the first sub-period.

The results using a one-week horizon are practically the same independently either employing RNDs or risk-adjusted densities. This probably makes sense. From the first order condition of the optimization problem of the representative agent, it is well known that pricing of risky assets may easily be consistent with a linear utility function or risk-neutralilty at high frequencies. Since consumption and risk aversion do not change much from week to week, we might expect that prices are well approximated as random walks. Of course, this result is very different once we allow for a longer investment horizon, where payoffs are scaled by the marginal rate of substitution of consumption. This is the intuition probably reflected in our empirical results.

Finally, we also estimate the ex-ante equity risk premium as it is perceived by investors. Using a period very similar to the sample period employed in this research, Santa-Clara and Yan (2005) have recently argued that the compensation for the realised volatility of the US stock market is about 60 percent of the risk perceived by the same investor when inferred from option prices. This implies that the risk investors perceived ex-ante and that are embedded in option prices is much higher than the realised risk. 
It should be noted that their methodology is highly parameterized. In particular, they assume that the stochastic volatility and the jump intensity follow a joint quadratic jump-diffusion process. Moreover, for tractability, they are forced to assume a power utility function. Our approach is much more flexible and allows us to analyse the robustness of our results to alternative preference specifications. It turns out that from October 1996 to December 2004, the ex-ante risk premium perceived by investors and that are embedded in option prices is between 12 and 18 percent higher than the premium required for compensating the same investors for the realised volatility in stock market returns. This is much lower that the one reported by Santa-Clara and Yan. Of course, their result suggests that the option market predicts a lot more crashes or negative jumps that the ones observed ex-post. Unfortunately, this may clearly be the result of the quadratic process assumed for jumps. In other words, their extreme results may be a consequence of the highly parameterized world they assume for the basic underlying factors driven their economy. On the contrary, our approach relies much more directly on option prices.

This paper is organized as follows. Section 2 briefly discusses how we estimate RNDs, while in Section 3 we present the testing procedures to assess the forecasting ability of our densities to check if they conform to the actual densities from which realisations are drawn. Section 4 discusses the basic option-implied preferences adjustments using stochastic discount factors, Section 5 contains the description of the data set used in the paper, and Section 6 reports the empirical results using risk-neutral and traditional risk-adjusted densities. Section 7 extends risk-adjustments to more complex specifications and discusses the perceived risk embedded in option prices. Conclusions follow in Section 8. 


\section{Estimating Risk-Neutral Densities}

Prices of European call options at time $t$ on the underlying asset $P$ with expiration at $t+\tau$ and strike prices $K$ are given by the well known expression ${ }^{1}$ :

$c(t, \tau, K)=e^{-r \tau} \int_{K}^{\infty} q_{t, \tau}\left(P_{t+\tau}\right)\left(P_{t+\tau}-K\right) d P_{t+\tau}$

where $q_{t, \tau}\left(P_{t+\tau}\right)$ is the risk-neutral probability density function for the value of the underlying asset at time $t+\tau$. As pointed out by Breeden and Litzenberger (1978), if we differentiate twice (1) with respect to $K$ we obtain the risk-neutral probability density function

$\frac{\partial^{2} c(t, \tau, K)}{\partial K^{2}}=e^{-r \tau} q_{t, \tau}\left(P_{t+\tau}\right)$

Given the similarities found in our own previous empirical evidence with the lbex 35 index between parametric and non-parametric estimation methods, this paper employs the two-lognormal mixtures of Melick and Thomas (1997) as the way to estimate RNDs,

$q_{t, \tau}\left(P_{t+\tau}\right)=\theta \log N\left(\alpha_{1}, \beta_{1} ; P_{t+\tau}\right)+(1-\theta) \log N\left(\alpha_{2}, \beta_{2} ; P_{t+\tau}\right)$

where $\log N\left(\alpha_{i}, \beta_{i} ; P_{t+\tau}\right)$ is the $i^{\text {th }}$ lognormal density with parameters $\alpha_{i}$ and $\beta_{i}$ :

$\alpha_{i}=\ln P_{t}+\left(\mu_{i}-\frac{1}{2} \sigma_{i}^{2}\right) \tau ; \beta_{i}=\sigma_{i} \sqrt{\tau} ; i=1,2$

and where $\mu_{i}$ and $\sigma_{i}$ are, respectively, the mean and standard deviation of associated normal distributions, and the stochastic process is based on two states with different first and second moments, governed by the weights $\theta$ and $1-\theta$ for $0 \leq \theta \leq 1$. Thus, this is a flexible specification for the RND that is able to capture skewness and excess kurtosis and allows for a rich and wide range of shapes including bi-modal distributions, which would appear if, for example, market participants are placing a high weight on an extreme move in the underlying price but are unsure of its direction.

Plugging this mixture of two-lognormals into equation (1) we can obtain theoretical prices for both calls and puts. Then, the numerical estimation of the five parameters, $\alpha_{1}, \beta_{1}, \alpha_{2}, \beta_{2}, \theta$, is obtained by minimizing the squared pricing error as defined by the difference between the theoretical and observed option prices:

$\min _{\left\{\alpha_{1}, \alpha_{2}, \beta_{1}, \beta_{2}, \theta\right\}}\left\{\sum_{j=i}^{N_{j}}\left[c_{j}\left(t, \tau, K_{j}\right)-c_{j}^{m}\right]^{2}+\sum_{h=i}^{N_{h}}\left[p_{h}\left(t, \tau, K_{h}\right)-p_{h}^{m}\right]^{2}\right\}$

subject to $\beta_{1}, \beta_{2}>0$ and $0 \leq \theta \leq 1$, and where $N_{j}, N_{h}, c_{j}^{m}$ and $p_{h}^{m}$ stand respectively for number of calls, number of puts, market price of call $j$ and market price of put $h^{2}$.

1. The same reasoning can of course be done in terms of put options. 


\section{$3 \quad$ Testing the Forecasting Performance of Probability Density Functions}

To study the predicting ability of estimated probability density functions (PDFs hereafter), both risk-neutral PDFs (RNDs hereafter) and risk-adjusted PDFs, we first employ a method based on the relationship between the data generating process (the true density function), $f_{t, \tau}\left(P_{t+\tau}\right)$, and the estimated sequence of density forecasts, $g_{t, \tau}\left(P_{t+\tau}\right)$, as related through the probability integral transform, $z_{t, \tau}$, of the realization of the process taken with respect to the density forecast, where $\tau$ represents the forecasting horizon. In other words, each cross-section of options at time $t$ for a given time-to-expiration $\tau$ produces an estimated PDF, $g_{t, \tau}\left(P_{t+\tau}\right)$. We want to test the hypothesis that our estimated $g_{t, \tau}\left(P_{t+\tau}\right)$ are equal to $f_{t, \tau}\left(P_{t+\tau}\right)$. Note of course that we have an estimated PDF for a given expiration and only one realization, $P_{t+\tau}$, is available on a given date and for that particular expiration. The probability integral transform is defined as

$z_{t, \tau}=\int_{-\infty}^{P_{t+\tau}} g_{t, \tau}(u) d u=Q_{t, \tau}\left(P_{t+\tau}\right)$

Hence, $z_{t, \tau}$ is equal to the probability value of the estimated cumulative density function, $Q_{t, \tau}(),. \tau$ days ahead at the realization of the underlying on day $t+\tau, P_{t+\tau}$. We basically integrate up to the realization of the underlying at each date and statistically check if the resulting probabilities are drawn from the estimated PDFs.

As shown by Diebold, Gunther and Tay (1998), under independence and if the forecasts and the true densities coincide, then the sequence of the probability integral transforms, $z_{t, \tau}$, is uniformly distributed as $U(0,1)$. Berkowitz (2001) proposes a parametric approach for jointly testing uniformity and independence. In particular, a further transformation, $x_{t, \tau}$, of the inverse probability transform, $z_{t, \tau}$, is defined using the inverse of the standard normal cumulative density function, $N($.$) :$

$x_{t, \tau}=N^{-1}\left(z_{t, \tau}\right)=N^{-1}\left(\int_{-\infty}^{P_{t+\tau}} g_{t, \tau}(u) d u\right)$

under the null of $g_{t, \tau}\left(P_{t+\tau}\right)=f_{t, \tau}\left(P_{t+\tau}\right), \quad x_{t, \tau}$ has an independent and identically distributed $\mathrm{N}(0,1)$. In order to estimate the independence and standard normality of the $x_{t, \tau}$, Berkowitz suggests the following autoregressive model ${ }^{3}$

$x_{t, \tau}-\mu=\rho\left(x_{t-1, \tau}-\mu\right)+\varepsilon_{t, \tau}$

2. Note that the mean of a RND is the future price. Some papers include in equation (5) the difference between the future price and the expected value of the underlying asset at $t+\tau$. In our sample the impact on the estimated parameters of the introduction of this additional term is negligible.

3. Berkowitz (2001) shows that higher order autoregressive processes results in increasing the number of parameters and reduced power. Also, Bliss and Panigirtzoglou (2004) compare alternative tests and conclude that the Berkowitz tests is more reliable in small samples. 
which is estimated using maximum likelihood and then testing the corresponding restrictions by a likelihood ratio test. The log-likelihood function, $L\left(\mu, \sigma^{2}, \rho\right)$, associated with the model is given by

$$
\begin{aligned}
L\left(\mu, \sigma^{2}, \rho\right)=-\frac{1}{2} \log (2 \pi) & -\frac{1}{2} \log \left[\frac{\sigma^{2}}{\left(1-\rho^{2}\right)}\right]-\frac{\left[x_{1, \tau}-\mu /(1-\rho)\right]^{2}}{2 \sigma^{2} /\left(1-\rho^{2}\right)}-\frac{n-1}{2} \log (2 \pi)-\frac{n-1}{2} \log \left(\sigma^{2}\right) \\
& -\sum_{t=2}^{T}\left[\frac{\left(x_{t, \tau}-\mu(1-\rho)-\rho x_{t-1, \tau}\right)^{2}}{2 \sigma^{2}}\right]
\end{aligned}
$$

Note that, under the assumptions of the model, $\mu=\rho=0$ and $\sigma^{2}\left(\varepsilon_{t, \tau}\right)=1$. Then, the likelihood ratio statistic, $L R=-2\left[L(0,1,0)-L\left(\hat{\mu}, \hat{\sigma}^{2}, \hat{\rho}\right)\right]$, is distributed as $\chi^{2}(3)$ under the null hypothesis.

When the available data implies that we have to test overlapping forecasts, a potential rejection may be due to the overlapping nature of the data, which may produce autocorrelation. Berkowitz also proposes to test the independence assumption separately by the alternative likelihood ratio statistic given by $L R(i)=-2\left[L\left(\hat{\mu}, \hat{\sigma}^{2}, 0\right)-L\left(\hat{\mu}, \hat{\sigma}^{2}, \hat{\rho}\right)\right]$ which is distributed as $\chi^{2}(1)$ under the null hypothesis.

As explained by Bliss and Panigirtzoglou (2004), if $L R$ rejects the hypothesis, failure to reject $L R(i)$ provides evidence that the estimated PDFs are not producing accurate forecasts of the true density. However, if both $L R$ and $L R(i)$ reject, it is not possible to conclude if there is lack of predicting ability or serial correlation. Finally, failure to reject both $L R$ and $L R(i)$ would be consistent with forecasting capacity.

Unlike most previous papers testing the forecasting ability of PDFs, we not only want to test the performance of the whole body of the distribution, but also analyze the performance of the tails of the distribution. We follow Anagnou, Bedendo, Hodges and Tompkins (2005) in employing the scoring rules based on the distance between the forecasted probability mass, $g_{t, \tau}^{\text {tail }}$, in a given tail and a binary variable, $R_{t, \tau}$, which takes the value of 1 if the actual realization of the underlying falls into the tail, and 0 otherwise. The so called Brier score is given by

$$
B=\frac{1}{T} \sum_{t=1}^{T} 2\left(g_{t, \tau}^{\text {tail }}-R_{t, \tau}\right)^{2}
$$

which takes values between 0 and 2 and a better performance is captured by smaller values for the score. To test if it departs from its expected value, $\sum_{t=1}^{T} g_{t, \tau}^{\text {tail }}\left(1-g_{t, \tau}^{\text {tail }}\right)$, the following statistic, suggested by Seillier-Moiseiwisch and Dawid (1993) is employed: 


$$
A S N=\frac{\sum_{t=1}^{T}\left(1-2 g_{t, \tau}^{\text {tail }}\right)\left(R_{t, \tau}-g_{t, \tau}^{\text {tail }}\right)}{\left[\sum_{t=1}^{T}\left(1-2 g_{t, \tau}^{\text {tail }}\right)^{2} g_{t, \tau}^{\text {tail }}\left(1-g_{t, \tau}^{\text {tail }}\right)\right]^{\frac{1}{2}}}
$$

which is asymptotically distributed as a standard normal. 


\section{Option-Implied Preferences Adjustments and the Empirical Stochastic Discount Factor}

The key idea of financial economics is that prices are generated by expected discounted payoffs,

$P_{t, \tau}=E_{t}\left[M_{t+\tau} X_{t+\tau}\right]$

where $X_{t+\tau}$ is a random payoff of any asset with price $P_{t, \tau}, M_{t+\tau}$ is the stochastic discount factor, which is the marginal rate of intertemporal substitution of aggregate consumption, and $E_{t}$ is the conditional expectation operator under the objective probability. As pointed out by Rosenberg and Engle (2002), the relative risk aversion of the representative investors written in terms of the stochastic discount factor is

$R R A=-\frac{\left[C_{t+\tau} M_{t+\tau}^{\prime}\left(C_{t+\tau}\right)\right]}{M_{t+\tau}\left(C_{t+\tau}\right)}$

where $C_{t+\tau}$ is aggregate consumption and $M_{t+\tau}^{\prime}$ is the derivative of the stochastic discount factor with respect to consumption.

In general, as discussed by Cochrane (2005), the stochastic discount factor will depend on current and future consumption and also on all state variables that affect marginal utility. Of course, the central debate on asset pricing is precisely over the variables that enter into the stochastic discount factor. Cochrane (2005) shows that any stochastic discount factor, and therefore the stochastic discount factor satisfying expression (12), can be represented as

$$
M_{t+\tau}\left(C_{t+\tau}\right)=M_{t+\tau}^{*}\left(X_{t+\tau}\right)+\varepsilon_{t+\tau}
$$

where $\varepsilon_{t+\tau}$ must be orthogonal to $X_{t+\tau}$. In other words, $M_{t+\tau}^{*}\left(X_{t+\tau}\right)$ is the projection of the stochastic discount factor $M_{t+\tau}\left(C_{t+\tau}\right)$ on the space of payoffs. If we identify future payoff with future price, which is quite appropriate when using data of options on futures as it will be the case in this research, we can write the pricing expression as,

$$
P_{t, \tau}=\int_{-\infty}^{\infty} M_{t+\tau}^{*}\left(P_{t+\tau}\right) f_{t, \tau}\left(P_{t+\tau}\right) P_{t+\tau} d P_{t+\tau}
$$

The so called projected relative risk aversion (PRRA hereafter), as defined by Rosenberg and Engle (2002), is therefore given by ${ }^{4}$,

4. The projected relative risk aversion reflects aversion to equity risk rather than aversion to consumption risk. 
$P R R A=-\frac{\left[P_{t+\tau} M_{t+\tau}^{*}{ }^{\prime}\left(P_{t+\tau}\right)\right]}{M_{t+\tau}^{*}\left(P_{t+\tau}\right)}$

The point of this discussion is of course justifying the use of prices rather than consumption in the preferences we employ to obtain risk-adjusted PDFs.

Using the risk-neutral density, $q_{t, \tau}\left(P_{t+\tau}\right)$, we write the generalization of equation (1) for any asset as,

$P_{t, \tau}=e^{-r \tau} \int_{-\infty}^{\infty} q_{t, \tau}\left(P_{t+\tau}\right) P_{t+\tau} d P_{t+\tau}$

As discussed by Jackwerth (2000) and Ait-Sahalia and Lo (2000), under dynamically complete and frictionless markets, the objective density function is related to the risk-neutral density function throughout the marginal rate of substitution of consumption of the representative investor. In our context, using expressions (15) and (17), it is easy to see that $f_{t, \tau}\left(P_{t+\tau}\right)$ is related to $q_{t, \tau}\left(P_{t+\tau}\right)$ by the following expression:

$$
f_{t, \tau}\left(P_{t+\tau}\right)=\frac{e^{-r \tau} q_{t, \tau}\left(P_{t+\tau}\right)}{M_{t+\tau}^{*}\left(P_{t+\tau}\right)}
$$

This is a very useful result because, given any of the two functions, we may infer the third one. Given a projected stochastic discount factor and some estimated RND, we modify slightly equation (18) to solve for the implied objective density function once is normalized to integrate to one ${ }^{5}$ :

$f_{t, \tau}\left(P_{t+\tau}\right)=\frac{\frac{e^{-r \tau} q_{t, \tau}\left(P_{t+\tau}\right)}{M_{t+\tau}^{*}\left(P_{t+\tau}\right)}}{\int \frac{e^{-r \tau} q(y)}{M^{*}(y)} d y}=\frac{\frac{e^{-r \tau} q_{t, \tau}\left(P_{t+\tau}\right)}{\lambda m_{t+\tau}\left(P_{t+\tau}\right)}}{\int \frac{e^{-r \tau} q(y)}{\lambda m(y)} d y}=\frac{\frac{q_{t, \tau}\left(P_{t+\tau}\right)}{m_{t+\tau}\left(P_{t+\tau}\right)}}{\int \frac{q(y)}{m(y)} d y}$

where $\lambda \equiv \rho / U^{\prime}\left(P_{t}\right)$ with $\rho$ being the subjective discount factor, and $m\left(P_{t+\tau}\right) \equiv U^{\prime}\left(P_{t+\tau}\right)$ being marginal utility defined over equity wealth.

From the specific functional form of the projected stochastic discount factor, and given the estimated RND, we may estimate the preference parameters that maximize the forecasting ability of the objective density. This also allows us to analyze the behaviour of the implied risk aversion and the implied (ex-ante) equity risk premium estimates over time.

5. A similar strategy is followed by Bliss and Panigirtzoglou (2004) using directly utility functions. 
Given the lack of consistently adequate forecasting ability of RNDs throughout the sub-periods analyzed by Alonso, Blanco and Rubio (2005), and in order to incorporate risk aversion into the analysis along the lines of Bliss and Panigirtzoglou (2004), we initially assume that the projected stochastic discount factor is characterized by either a power or an exponential function. Later on the paper, time-varying projected risk aversion specifications will be also proposed.

Given an estimation of a RND from a cross-section of option prices on the index, we look for the implied preferences that force the preference-adjusted density to be as close as possible to the distribution of realizations of the underlying as defined by the Berkowitz test statistic. In other words, we choose the preference parameters from the assumed projected stochastic discount factor to maximize the predicting ability of the estimated density by maximizing over the $p$-value of the Berkowitz $L R$ statistic.

In the empirical exercise below we assume initially a projected stochastic discount factor based on the well known power utility function,

$m\left(P_{t+\tau}\right)=P_{t+\tau}^{-\gamma}$

where $\gamma$ is the constant projected relative risk aversion coefficient. These preferences, although convenient, are known to have serious problems in explaining both the temporal and cross-sectional behaviour of asset prices. Among other things, it seems that the assumption about the time-invariant behaviour of the risk aversion coefficient is not empirical reasonable. It is not surprising then, that the empirical evidence of implied risk aversion estimates of Bliss and Panigirtzoglou (2004) and Jackwerth (2000) is very controversial.

We also assume a projected stochastic discount factor based on the exponential utility function,

$$
m\left(P_{t+\tau}\right)=e^{-\gamma P_{t+\tau}}
$$

with projected relative risk aversion given by $\gamma P_{t+\tau}$. Of course, this function has increasing relative risk aversion and constant absolute risk aversion. Together with the assumption of normal stock returns this is also a tremendously popular specification of preferences. However, as before, implied risk aversion estimates tend to increase in periods of reduced market uncertainty and short horizons. 
In this research, we employ the European-style Spanish equity option contract on the IBEX 35 futures which is one of the largest options equity market within the euro area. The Spanish IBEX 35 index is a value-weighted index comprising the 35 most liquid Spanish stocks traded in the continuous auction market system. The official derivative market for risky assets, which is known as MEFF, trades a futures contract on the IBEX 35, the corresponding option on the IBEX 35 futures contracts for calls and puts, and individual futures and option contracts for blue-chip stocks. The option contract on the IBEX 35 futures is a cash settled European option with trading over the three nearest consecutive months and the other three months of the March-June-September-December cycle. The expiration day is the third Friday of the contract month. The multiplier is $1 €$ and the exercise prices are given by 50 index point intervals. Our database is comprised of settlement IBEX 35 index futures prices, the associated settlement prices of all call and put options traded on each day, and the implied volatility for each option. Moreover, for each option we also have the expiration date and the associated strike. At expiration, the options settle to the exchange delivery settlement future price determined by MEFF by calculating the arithmetic average between 16:15 and 16:45 taking an index value per minute. This series is employed to compute the payoffs of the future in this work.

The options prices employed throughout our research are the MEFF-reported settlement prices. The implied volatility for all at-the-money options reflects the closing market price of each option. For the rest of strikes, MEFF linearly approximates the implied volatility by two segments. Two different slopes are employed for strikes corresponding to options in-the-money and out-of-the-money. The slopes are obtained according to the closing market conditions of the market on each Friday which will be the day from which forecasts are made in our study. The settlement prices are calculated using Black's (1976) formula, the underlying settlement price and the previous volatilities. Therefore, by construction all options reflect closing market conditions and are synchronous with the underlying asset price. The data cover the period from October 1996 through December 2004; i.e., 99 months $^{6}$.

Option settlement prices are available for expirations from one week to one year. It is very important to point out that a target observation date in the study is determined one, four or eight weeks before every option expiration date. The number of strikes ranges between 28 (23) and 211 (211) with an average of 105 (103) for one week (four and eight weeks). Options with expires of less than three months, expire at monthly intervals. Hence, forecasts and realizations for horizons less than or equal to one month may be expected to be independent. The number of cross-sections is 99 for forecasts horizons of either one or four weeks. This is similar to the cross-sections employed by Bliss and Panigirtzoglou (2004) in the case of their data on FTSE 100, and slightly more than half of the available cross-sections for options on the S\&P 500.

6. Before October 1996 MEFF computed settlement prices using constant implied volatilities. 


\subsection{The Empirical Performance of Risk-Neutral Densities}

In order to determine whether there is evidence that the RNDs adequately forecast the distribution of ex-post realizations of the underlying index, we employ the Berkowitz test statistics discussed in Section 3. Table 1 shows the empirical results using the mixture of two lognormals as the estimation of RNDs for the Spanish stock IBEX 35 index. For the whole sample period, we cannot reject the hypothesis that the RNDs provide accurate predictions of the distributions of future realizations of the IBEX-35 index at the three horizons considered (one, four and eight weeks). On the one hand, the $L R$ test statistic does not support that the RND forecasts poorly the actual realizations. At the same time, by looking at the $L R(i)$ statistics we cannot reject the hypothesis that the probability integral transforms are uncorrelated. Hence, we divide the whole sample period into two non-overlapping sub-periods from October 1996 to March 2000, and from April 2000 to December 2004. This allows us to check the robustness of the surprising results found for the complete sample. As reported in Table 1, in the first sub-period the Berkowitz test rejects the hypothesis that the RNDs are good forecasts of future realizations of the IBEX-35 index at four- and eight-week horizons. Moreover, the $L R(i)$ shows that the reason for rejecting is not the violation of the independence assumption underlying the test statistic. This result is consistent with the intuition that RNDs are very unlikely to adequately capture the future behaviour of equity prices. It seems reasonable to expect that the stock market prices risks ${ }^{7}$. This result also confirms that the Berkowitz test has sufficient power to reject the null hypothesis. Finally, as in the case of the complete sample, the $L R$ statistic is not able to reject the good predictive performance of the RNDs during the second sub-period. This is interesting since the years of the second sub-period coincide with a continuous negative performance of the stock market, and the opposite occurred from October 1996 to March 2000. It seems that during the first sub-period, the high levels reached by the stock market make RNDs unable to place enough probability on the right tail of the distribution relative to actual realizations. This would explain the poor performance of the RNDs during the first half of the sample. We will investigate this potential explanation by analyzing the behaviour of the tails.

As before, the results using a one-week horizon are not robust to alternative sub-periods. Surprisingly, however, the rejection of the null is now associated with the second sub-period. With a very short forecasting horizon noise may be playing a distorting impact on the results.

Table 2 contains the results from the tests designed to analyze the misspecification of the estimated RNDs and risk-adjusted densities on the tails of the distribution. For the right and left tails and for both tails we compare the frequency with which realizations lie on those areas with the probability mass assigned by the estimated densities. We also report the test statistic given by equation (11). The tests indicate that, using the risk-neutral specification and for the four- and eight-week horizons, the probability mass assigned by our estimated RND to the right tail during the first sub-period significantly underestimates the frequency of actual realizations. In other words, the strikingly good performance of the stock market during the first sub-period is not adequately forecasted by the RNDs estimated from option prices. For the right tail of the distribution the same results are observed for the full sample period

7. See the recent evidence of Ghysels, Santa-Clara and Valkanov (2005) for the US market, and León, Nave and Rubio (2006) for European markets. 
using the four-week horizon. These results are consistent with the evidence reported for the full body of the implied RNDs. There seems to be a good performance of RNDs from April 2000 to December 2004, and a relatively bad performance of our estimated RND during the bull market of the first sub-period which may be explained by the high frequency of realizations on the right tail of the distribution. Of course, this would be expected since those differences may be arising from the risk aversion of the representative investor.

By contrast, at the one-week horizon the probability mass assigned by our estimated RND to the right tail does not seem to understate the frequency of actual realizations, especially during the second sub-period. Interestingly, the test shows that the probability with which realizations lie on both tails is overestimated. This is the case for both the full period, and especially, for the second sub-period. This evidence suggests that rejection that RNDs provide good forecasts at the one-week horizon during the second sub-period does not seem to be related to the implied risk-neutrality assumption which is more directly applicable to the results on individual tails. On the contrary, this result seems to suggest that volatility is overestimated.

All in all the evidence presented in Tables 1 and 2, which of course is consistent to that reported in Alonso, Blanco and Rubio (2005), suggests that a risk premium adjustment might be needed at the four- and eight-week horizons to adequately forecast future outcomes but this does not seem to be the case for the one-week horizon. Sub-section 6.2 investigates this issue.

\subsection{Risk-Adjusted Densities}

First we implicitly estimate the parameters and risk aversion of the two alternative utility functions. We employ a process of searching for the optimal level of $\gamma$ to maximize the predicting ability of the resulting risk-adjusted densities by maximizing over $\gamma$ the $p$-value of the Berkowitz statistics ${ }^{8}$.

Panel A of Table 3 contains the estimated parameters for the two specifications employed. In all cases, the estimated parameters are higher when using a one-week horizon, a disturbing result also obtained by Bliss and Panigirtzoglou (2004). More interesting are the risk aversion estimates reported in Panel B of Table 3. The mean (median) of both power and exponential functions over the whole sample period are very similar. The implied projected risk aversion estimates for a one-week horizon are around 3.5, while they are close to 1.7 when a four-week and eight-week horizons are imposed. Of course, as pointed out above, the PRRA under the exponential function is $\gamma P_{t+\tau}$. For this reason we provide a range for the risk aversion estimate over the sample period that depends on the associated values of the underlying. Interestingly, the mean values are similar to the levels estimated under the power specification.

Figure 1 compares the estimated PDFs for two different expiration days at a four-week horizon. Panel A shows PDFs estimated with option prices of 24/8/2001; i.e., before the terror attacks of September 11th. On that day, all PDFs have a similar shape. Of course, risk-adjusted PDFs appear (slightly) shifted to the right. Panel B shows PDFs estimated with option prices of 21/9/2001, which reflected the impact on market prices of the events of September 11th. Compared with panel A, the probability mass of the tails, and especially on the left tail, is much higher reflecting the higher uncertainty. As expected by the

8. This process does not provide a measure of whether the resulting parameters are significantly different from zero. A Monte Carlo simulation must be employed to obtain the distribution of generated p-values. 
definition of risk-neutral probabilities, risk-adjusted PDFs display lower left-skewness than those of the RND, pointing out that the latter distribution overstates poor states of nature, especially during stress economic periods. Of course, marginal utility is higher in those scenarios and this is precisely what is introduced into our estimated RNDs. Finally, this figure illustrates that the risk adjustments used in this paper is more subtle than a simple mean shift. Interestingly, the left-skewness associated with power preferences is slightly lower than the adjustment under exponential preferences. In this sense, the risk-adjustment seems to be stronger under power utility than under the exponential case in stress market periods.

The difference between the mean of the risk-adjusted PDF and the mean of the RND, normalised by the mean of the RND, is an approximate measure of the ex-ante equity risk premium implied by estimated PDFs. Figure 2 displays the time-series of the four-week horizon risk-premium for the two adjustments methods, together with the at-the-money implied volatility. Three features emerge from this figure. First, both risk-adjustment methods produce similar risk premia. Second, the risk premia mirror developments in implied volatility, reflecting the fact that investors demand a higher risk premium in periods of higher uncertainty. Third, the risk premium for the power (exponential) preferences show a relatively high volatility over time with annualized values ranging between 1.96 (2.03) percent and 44.3 (42.9) percent. The annualized mean is also relatively high and equal to 11.5 (11.7) percent. We will come back to these estimates later in the paper.

Panels A and B of Table 4 present the Berkowitz tests using the power and exponential functions, respectively. The results are strikingly similar for both specifications. As in the case of risk-neutral densities, for the whole period we cannot reject the hypothesis that risk-adjusted densities are good predictors of future realizations of the underlying index for the three horizons. However, contrary to the RNDs case, the key evidence for the fourand eight-week horizons is that risk-adjusted densities also provide adequate forecasting ability for both sub-periods. The results are clearly consistent with the need for a risk premium adjustment. On the other hand, what is certainly surprising is that the specific risk-adjustment imposed does not seem to be relevant when trying to improve the forecasting ability of alternative risk-adjusted densities.

Finally, for the very short horizon of one-week, it is quite clear that risk-adjustments are not the issue when forecasting throughout either risk-neutral or risk-adjusted densities. As mentioned in the introduction, this should be expected since the quantity of risk embedded in one week is probably negligible compared to the quantity of risk for the other two horizons. The results are identical independently of whether risk-adjustments are taken into account or not suggesting that rejection of the null during the second sub-period is not related to the risk-neutrality assumption.

Table 5 contains the results from the tests designed to analyze the misspecification of the estimated risk-adjusted densities on the tails of the distribution. As before, the qualitative results reported in Panels $A$ and $B$ of Table 5 are the same independently of the actual preference specification employed.

However, risk-adjusted densities perform better than RNDs at the four- and eight-week horizons. In particular, for the complete sample period, the difference between the actual frequency observed on the right tail and the probability mass assigned by our estimated densities is not statistically significant. Again, by recognizing the existence of a 
risk premium we improve the forecasting ability of our estimated densities. However, for the bull market of the first sample period, the true distribution assigns more probability to high returns than the estimated risk-adjusted densities. In any case, at the four-week horizon, the probability mass into the right-tail is slightly lower for the risk-adjusted PDFs than for the RNDs counterparts. Moreover, at the eight-week horizon the difference between the actual frequencies and the assigned probability under risk-adjusted densities is not statistically different from zero, which is again an improvement relative to the risk-neutral case. Finally, the results in the tails of the distribution for a one-week horizon are again quite similar independently of using RNDs or the risk-adjusted counterparts.

So far we have used a specification for the projected stochastic discount factor which assumes a time-invariant relative risk aversion coefficient. To examine the robustness of this assumption we follow Bliss and Panigirtzoglou (2004) and divide the sample into two equal-sized sub-samples corresponding to periods of high and low volatility, proxied by the implied volatility of the at-the-money options. In each sub-sample we independently estimate the PRRAs using the previous approach. Table 6 presents the estimated PRRAs for these two sub-samples. For every horizon and for both specifications the low-volatility PRRAs exceed the high-volatility PRRAs, a result consistent with the evidence reported by Bliss and Panigirtzoglou (2004).

This inverse relationship between equity risk and risk aversion is a surprising result. The intuition suggests exactly the opposite, i.e. during periods of high uncertainty investors became more risk averse. As suggested by Bliss and Panigirtzoglou (2004), a possible explanation is that the representative investor is changing with volatility. In particular, it might happen that during periods of high volatility the more risk-averse investors left the market resulting in a lower average level of risk aversion among the remaining investors, and therefore in a lower level of risk aversion of the marginal or representative investor.

In any case, these results provide evidence against the assumption of constant risk aversion parameters and, therefore, suggest that a risk-adjustment with time-varying risk-aversion parameters could improve the forecasting ability of the risk-adjusted PDFs.

Figure 3 displays the time-series of the four-week horizon risk-premium computed with the risk-adjusted PDFs estimated dividing the sample in two sub-periods as before. Two main differences are apparent when comparing Figure 3 with Figure 2. First, the relationship between risk premium and volatility is less marked, although the periods of high volatility still coincide with those of higher risk premia. Second, a lower range of fluctuation of risk premium is observed in Figure 3. This finding suggests that risk adjustments based on constant risk aversion parameters imply an excessive volatility of risk premia. Moreover, the annualized average risk-premium is 10.2 percent under the two alternative values of risk aversion linked to the two levels of implied volatility rather than 11.5 percent when a fixed relative risk aversion coefficient is employed. 


\section{Alternative Stochastic Discount Factors with Time-Varying Projected Risk}

\section{Aversion}

\subsection{Habit-based Stochastic Discount Factor Specification}

The projected risk-adjustments employed above, although convenient, are inspired on utility functions which are known to have serious problems in explaining both the temporal and cross-sectional behaviour of asset prices. Among other things, it seems that the assumption about the time-invariant behaviour of the risk aversion coefficient may not be empirically reasonable.

In this study we assume a projected habit-based stochastic discount factor for which marginal utility is given by:

$$
m\left(P_{t+\tau}\right)=\left(P_{t+\tau}-H_{t+\tau}\right)^{-\gamma}
$$

where $H_{t+\tau}$ is the level of habit, and $\gamma$ reflects the projected utility curvature parameter based on equity risk rather than consumption risk ${ }^{9}$.

Our problem to incorporate a counter-cyclical time-varying projected risk aversion is to define a reasonable level of habit which should be lower than the current level of the stock exchange index by construction. The habit-based pricing models employ the so called surplus consumption ratio which is a recession variable defined in our context as

$$
S_{t+\tau}=\frac{P_{t+\tau}-H_{t+\tau}}{P_{t+\tau}}
$$

Then, under an external specification of habit, expression (22) may also be written as,

$$
m\left(P_{t+\tau}\right)=P_{t+\tau}^{-\gamma} S_{t+\tau}^{-\gamma}
$$

It is clear that $S_{t+\tau}$ should be always positive independently of the level of the stock index. Hence, when habit is close to the actual level of financial wealth, which may be an indication of a bear market, investors become more risk averse. This is precisely the time-varying behaviour we need to capture in any reasonable stochastic discount factor specification.

In order to incorporate habit in our estimations, we follow a paper by Chen and Ludvigson (2004) on testing pricing models with consumption and habit preferences. We first note that habit may reasonably depend upon the past levels of financial wealth:

$H_{t+\tau}=h\left(P_{t+\tau}, P_{t+\tau-1}, \ldots, P_{t+\tau-L}\right)$

9. See Campbell and Cochrane (1999) for a formal treatment of external habit utility specifications. 
However, the level of the stock exchange index is trending, so it becomes necessary to transform the model to use stationary data on the stock index, such as observations on stock level growth. We assume that the unknown function $h$ is homogeneous of degree one, and this allows us to write habit as

$$
H_{t+\tau}=P_{t+\tau} g\left(\frac{P_{t+\tau-1}}{P_{t+\tau}}, \ldots ., \frac{P_{t+\tau-L}}{P_{t+\tau}}\right)
$$

According to our previous reasoning we need to ensure that $H_{t+\tau}<P_{t+\tau}$. A reasonable function would be the following:

$$
g(x)=\beta\left(1+e^{-x}\right)^{-1}
$$

where $\quad x=\left(\delta \frac{P_{t+\tau-1}}{P_{t+\tau}}+\delta^{2} \frac{P_{t+\tau-2}}{P_{t+\tau}}+\ldots .+\delta^{L} \frac{P_{t+\tau-L}}{P_{t+\tau}}\right), \quad 0 \leq \beta \leq 1, \quad 0 \leq \delta \leq 1, \quad$ and $0 \leq g(x) \leq 1$. Therefore, independently of $\beta$ and $\delta$ we have that $H_{t+\tau}<P_{t+\tau}$. It is important to note that both Chen and Ludvigson (2004) and Menzly, Santos and Veronesi (2004) show that non-linear specifications of the external habit model helps explaining better the cross-section of asset returns.

To summarize, the habit-inspired specification is given by

$H_{t+\tau}=P_{t+\tau} \beta\left(1+e^{-\left(\delta \frac{P_{t+\tau-1}}{P_{t+\tau}}+\delta^{2} \frac{P_{t+\tau-2}}{P_{t+\tau}}+\ldots .+\delta^{L} \frac{P_{t+\tau-L}}{P_{t+\tau}}\right)}\right)^{-1}$

Given the similar results we have obtained so far for four and eight week horizons, in the empirical exercises performed in this Section, we concentrate on the four week horizon. In exercises based on expression (28) we impose $\delta=0.70$ and $L=12$. Moreover, $\beta$ and $\gamma$ are freely estimated to maximise as before the $\mathrm{p}$-value of the Berkowitz statistic ${ }^{10}$.

\subsection{Ad-hoc Time-Varying Projected Risk Aversion}

The idea is again to allow for a time-varying behaviour on the projected risk aversion coefficient. The projected stochastic discount factor is now given by,

$m\left(P_{t+\tau}\right)=P_{t+\tau}^{\gamma_{t}+\tau}$

where we assume two alternative specifications for $\gamma_{t+\tau}$. In the first one (model 1), $\gamma_{t+\tau}$ is assumed to be a function of current and past value of the stock exchange index, while in the second specification (model 2), $\gamma_{t+\tau}$ is assumed to depend on current at-the-money

10. The estimated values of these two parameters turn out to be 0.728 and 1.233 , respectively. 
implied volatility $(M)$. Once again, the idea is to incorporate a time-varying behaviour on $\gamma_{t+\tau}$ which is suggested by our previous evidence. More specifically, model 1 is characterised by $\gamma_{t+\tau}=\gamma\left(P_{t}, P_{t-1}, \cdots, P_{t-L}\right)$ where

$\gamma_{t+\tau}=\alpha\left(1+e^{x_{t}}\right), x_{t}=\eta\left(\frac{P_{t-1}+\delta P_{t-2}+\cdots+\delta^{L-1} P_{t-L}}{\left(1+\delta+\cdots+\delta^{L-1}\right) P_{t}}\right)$

for $\alpha>0,0 \leq \delta \leq 1$ and free $\eta$. Note that this specification ensures that the time-varying parameter $\gamma_{t+\tau}$ is positive. Parameter $\eta$ governs the relationship between $\gamma_{t+\tau}$ and the stock exchange cycle, proxied by the ratio between a weighted average of the past values of the stock exchange index and the current level of that index. Again, these parameters are estimated to maximise the $\mathrm{p}$-value of the Berkowitz statistic ${ }^{11}$.

Alternatively, model 2 assumes that $\gamma_{t+\tau}=\gamma\left(I V_{t}\right)$ where

$\gamma_{t+\tau}=\alpha I V_{t}^{\eta}$

for $\alpha>0$ and free $\eta$. Let us imagine a simple conditional CAPM world where the excess market return is given by,

$E_{t}\left(r_{m t+\tau}\right)=\gamma_{t+\tau} \operatorname{Var}_{t}\left(r_{m t+\tau}\right)$

If $\eta=0$ then $\gamma_{t+\tau}$ is constant, which according to (32) implies that all uncertainty in the market captured by implied volatility will be impounded into the market risk premium. This is precisely what we observe in Figure 2. On the other hand, if $\eta=-2$, by plugging (31) into (32) we get that

$E_{t}\left(r_{m t+\tau}\right)=\frac{\alpha}{I V_{t}^{2}} \operatorname{Var}_{t}\left(r_{m t+\tau}\right) \cong \alpha$

and the expected risk premium would be approximately constant. Therefore, under this specification, we may check whether imposing less variability in the expected market risk premium improves the forecasting capacity of the risk-adjusted density functions.

\subsection{The Empirical Evidence of Alternative Risk-Adjustments}

The comparison between the forecasting ability of alternative risk-adjustments using a four-week horizon is reported in Table 7 . The Berkowitz statistics clearly show that all adjustments obtain quite similar results. We can never reject the hypothesis that risk-adjusted densities are good predictors of future realizations of the underlying index. This is the case independently of the period analysed. For the first sub-period, the p-values are slightly lower when the traditional models are employed. However, the opposite results are found for the

11. The estimated values of these parameters are $1.358,1.000$ and -1.267 , respectively. 
second sub-period. Hence, it seems that the bull market experienced between October 1996 and March 2000 is somehow better captured with a rather stable risk premium. The p-value imposing a constant risk premium with model 2 and $\eta=-2$ is 0.18 while it is only 0.11 for the power specification. A similar result is obtained for the whole period.

Figure 4 contains the ex-ante risk premia implied by the five competing risk-adjustments for the four-week horizon. As before, it is estimated as the difference between the mean of the corresponding risk-adjusted PDF and the mean of the RND, normalised by the mean of the RND. The risk premium under the habit-inspired preferences is very similar to the one obtained by the classic power specification. It is slightly less extreme but otherwise they are practically identical. The same result is found when we use model 1 in which the projected risk aversion depends on the current and past values of the stock exchange index. Much less variability is reported when we employ model 2 for $\eta=-1$ and, of course, for $\eta=-2$. Thus, despite the fact that all risk-adjusted density forecasts present an undistinguishable statistically performance, the implied variability of the ex-ante risk premium is different among alternative stochastic discount factors specifications.

Table 8 reports the annualized average risk premium for all models employed and their range of variability. Our results are in spirit closely related to the evidence recently reported by Santa-Clara and Yan (2005). They argue that the risks perceived ex-ante by investors are much larger than the realised risk. If investors do price the stock market to generate enough return to compensate them for the perceived level of risk rather than for the actual level of risk, the equity premium can be easily much higher. Of course, the perceived market risk can be obtained using option prices. They propose a much parameterised behaviour for diffusive risk, captured by a Brownian motion, and jump risk, modelled as a Poisson process. The important point of their paper is that they assume that the intensity of the jump arrivals is also stochastic and interdependent with stochastic volatility. In particular, they assume that the stochastic volatility and the jump intensity follow a joint quadratic jump-diffusion process which is the square of linear Gaussian process. Moreover, for tractability they impose a power utility function defined over stock market wealth with a relative risk aversion coefficient of 1.92 for the period between January of 1996 and December of 2002.

Their model suggests an unconditional annualised equity risk premium of 11.8 percent which is 40 percent higher than the risk premium necessary to compensate the same investor for the realised volatility of the market. Interestingly, the jump component is a little bit more than half of the equity premium and it presents a very similar range of variation than the equity premium itself. The equity premium ranges between 0.3 and 54.9 percent while the jump component of the premium varies between zero and 45.4 percent. Stock returns includes a premium for the negative jump-intensity states perceived ex-ante by investors that did not materialise in the actual sample. They conclude that ex-ante perceived risk embedded in option prices far exceed any level of reasonable risks. A new puzzle arises in the empirical asset pricing literature.

We show that, using a rich family of alternative stochastic discount factors and for a very similar sample period, the risk premium perceived ex-ante as embedded in option prices is lower than the one reported by Santa-Clara and Yan (2005). Given our data, an investor with sample average relative risk aversion and realised annual market volatility of 24.5 percent 
requires a 10.2 percent risk premium ${ }^{12}$. Depending upon the stochastic discount factor imposed in our estimations, the perceived ex-ante risk premium ranges between 11.5 percent for the power case to 12.5 percent for the time-varying risk aversion as a function of current implied volatility with $\eta=-1$. These are between 12 and 18 percent higher than the risk premium necessary to compensate the same investor for the realised volatility of the Spanish market. This is of course much lower than the numbers reported by Santa-Clara and Yan. They may have found a puzzling high risk implied by option prices. However, the puzzle is probably much less dramatic than the one suggested by their paper. Therefore, in their own words, the option markets cry wolf just a little more (not a lot more) often than the wolf actually shows up. Our result is also consistent with the fact that the risk-adjusted probability mass assigned to the left tail under a four-week horizon is higher but not statistically different from the frequency with which actual observations fell in that area.

12. The realised volatility of the stock market during our sample period was 24.48 percent. Hence, the risk premium required to compensate that level of risk is $0.2448^{2} \times 1.70=0.1019$. 


\section{Conclusions}

Option prices provide information about how investors assess the likelihood of alternative outcomes for future market prices of underlying assets. The main objective of this paper is to analyse the value of information contained in prices of options on the IBEX 35 index at the Spanish Stock Exchange Market. The forward looking information is extracted using implied risk-neutral density functions estimated by a mixture of two-lognormals. Moreover, several alternative risk-adjustments including the power, exponential and habit-inspired based stochastic discount factors are analysed. Additionally, two ad-hoc models in which the projected relative risk aversion is allowed to be time-varying are estimated. In model 1, risk aversion is a function of current and past levels of the stock market index. In model 2, risk aversion is a function of current implied volatility where the exponential is assumed to be either -1 or -2 . In this later case, the ex-ante estimated risk premium is approximately constant.

Our results show that between 1996 and 2004, we cannot reject the hypothesis that the RNDs provide accurate predictions of the distributions of future realisations of the IBEX 35 index at one-, four- and eight-week horizons. Interestingly, when the whole period is divided into two sub-periods, we find that RNDs are not able to consistently predict the excellent behaviour of the stock market from October 1996 to March 2000 at the four-and eight-week horizons. In this period, option prices assign a low risk-neutral probability to large rises compared with realisations. On the other hand, RNDs are good predictors of realizations for the period between April 2000 and December 2004 at the same horizon. This suggests that the overall ability of RNDs as a forecasting device is just a consequence of two distinct sub-periods compensating each other.

These results tend to confirm the necessity of risk premium adjustments at four- and eight-week horizons. When forecasting through risk-adjusted densities the performance of the first sub-period is statistically improved. Independently of the stochastic discount factor employed, we cannot reject the hypothesis that risk-adjusted densities provide adequate predictions of the distributions of future realisations of the IBEX 35 index at these horizons. What is more important, and contrary to the RNDs, the results are consistent throughout sub-periods. All risk-adjusted densities generate similar forecasting statistics. At the one-week horizon risk adjustments do not improve the forecasting ability of RNDs, suggesting that at very short horizons the assumption of risk-neutrality is reasonable.

Finally, the ex-ante risk premium perceived by investors is between 12 and 18 percent higher than the premium required to compensating the same investor for the realised volatility. This compensation is independent of the volatility of the ex-ante market risk premium. Hence, option prices may contain implicitly a higher risk than the one required by a similar investor for realized volatility. However, this excess perceived risk embedded in option prices does not seem to be as dramatic as reported previously in literature. 


\section{REFERENCES}

AïT-SAHALIA, Y., and A. LO (2000). "Nonparametric risk management and implied risk aversion", Journal of Econometrics, 94, pp. 9-51.

ALONSO, F., R. BLANCO and G. RUBIO (2005). Testing the forecasting performance of IBEX 35 option-implied risk-neutral densities, Working Paper Series, No. 0505, Banco de España.

ANAGNOU, I., M. BEDENDO, S. HODGES and R. TOMPKINS (2005). "Forecasting accuracy of implied and GARCH-based probability density functions", Review of Futures Markets, 11, pp. 41-66.

BERKOWITZ, J. (2001). "Testing density forecasts with applications to risk management", Journal of Business and Economic Statistics, 19, pp. 465-474

BLACK, F. (1976). "The pricing of commodity contracts", Journal of Financial Economics, 3, pp. 167-179.

BLISS, R., and N. PANIGIRTZOGLOU (2002). "Testing the stability of implied probability density functions", Journal of Banking and Finance, 26, pp. 381-422.

BLISS, R., and N. PANIGIRTZOGLOU (2004). "Option-implied risk aversion estimates", Journal of Finance, 59, pp. 407-446

BREEDEN, D., and R. LITZENBERGER (1978). "Prices of state contingent claims implicit in option prices", Journal of Business, 51, pp. 621-652

BONDARENKO, O. (2003). "Estimation of risk-neutral densities using positive convolution approximation", Journal of Financial Econometrics, 116, pp. 85-112.

CAMBPELL, J., and J. COCHRANE (1999). "By force of habit: A consumption-based explanation of aggregate stock market behavior", Journal of Political Economy, 107, pp. 205-251.

CHEN, X., and S. LUDVIGSON (2004). Land of addicts? An empirical investigation of habit-based asset pricing models, Working Paper, Department of Economics, New York University.

COCHRANE, J. (2005). Asset pricing (revised edition), Princeton University Press.

CRAIG, B., E. GLATZER, J. KELLER and M. SCHEICHER (2003). The forecasting performance of German stock option densities, Discussion Paper No.17, Studies of the Economic Research Centre, Deutsche Bundesbank.

DIEBOLD, F., T. GUNTHER and A. TAY (1998). "Evaluating density forecasts, with applications to financial risk management", International Economic Review, 39, pp. 863-883.

GHYSELS, E., P. SANTA-CLARA and R. VALKANOV (2005). "There is a risk-return tradeoff after all”, Journal of Financial Economics, 76, pp. 509-548

JACKWERTH, J. (2000). "Recovering risk aversion from option prices and realized returns", Review of Financial Studies, 13, pp. 433-451.

KANG, B., and T. KIM (2006). "Option-implied risk preferences: an extension to wider classes of utility functions", Journal of Financial Markets, 9, pp. 180-198.

LEÓN, A., J. NAVE and G. RUBIO (2006). "The relationship between risk and expected return in Europe", forthcoming in the Journal of Banking and Finance.

MELICK, W., and C. THOMAS (1997). "Recovering an asset's implied PDF from option prices: an application to crude oil during the Gulf crisis", Journal of Financial and Quantitative Analysis, 32, pp. 91-115.

MENZLY, L., T. SANTOS and P. VERONESI (2004). "Understanding predictability", Journal of Political Economy, 112 pp. 1-47.

ROSENBERG, J., and R. ENGLE (2002). "Empirical pricing kernels", Journal of Financial Economics, 64, pp. $341-372$.

SANTA-CLARA, P., and S. YAN (2005). Crashes, Volatility, and the Equity Premium: Lessons from S\&P 500 Options, Working Paper, The Anderson School of Business, University of California at Los Angeles

SEILLIER-MOISEIWISCH, F., and P. DAWID (1993). "On testing the validity of sequential probability forecasts", Journal of the American Statistical Association, 88, pp. 355-359.

SHACKLETON, M., S. TAYLOR and P. YU (2006). A multi-horizon comparison of density forecasts for the S\&P500 using index returns and option prices, Working Paper, Department of Accounting and Finance, Lancaster University, England. 


\section{Table 1: Berkowitz Tests for Risk-Neutral Densities Estimated with a Mixture}

of Two Lognormals

October 1996-December 2004

The reported LR value is the Berkowitz likelihood ratio test for i.i.d. normality of the inversenormal transformed inverse probability transforms of the realizations as given by $L R=-2[L(0,1,0)-L(\mu, \sigma, \rho)]$ which is distributed as a $\chi^{2}(3)$.The $L R(i)$ statistic is the Berkowitz likelihood ratio test for independence. Rejection of the test for independence suggests that rejection of the density as a good forecast may be due to serial correlation rather than poor forecasting performance.

\begin{tabular}{|c|c|c|c|c|c|c|}
\hline \multirow{2}{*}{$\begin{array}{l}\text { Forecast } \\
\text { Horizon }\end{array}$} & \multicolumn{2}{|c|}{ Oct. 1996-Dec. 2004} & \multicolumn{2}{|c|}{ Oct. 1996-Mar. 2000} & \multicolumn{2}{|c|}{ Apr. 2000-Dec. 2004} \\
\hline & $\begin{array}{c}\text { LR } \\
\text { (p-value) }\end{array}$ & $\begin{array}{c}\mathrm{LR}(\mathrm{i}) \\
\text { (p-value) }\end{array}$ & $\begin{array}{c}\text { LR } \\
\text { (p-value) }\end{array}$ & $\begin{array}{c}\mathrm{LR}(\mathrm{i}) \\
\text { (p-value) }\end{array}$ & $\begin{array}{c}\text { LR } \\
\text { (p-value) }\end{array}$ & $\begin{array}{c}\text { LR(i) } \\
\text { (p-value) }\end{array}$ \\
\hline 1 week & $\begin{array}{l}4.59 \\
(0.20)\end{array}$ & $\begin{array}{l}0.91 \\
(0.34)\end{array}$ & $\begin{array}{l}3.53 \\
(0.32)\end{array}$ & $\begin{array}{c}0.34 \\
(0.56)\end{array}$ & $\begin{array}{l}12.76 \\
(0.01)\end{array}$ & $\begin{array}{c}0.30 \\
(0.59)\end{array}$ \\
\hline 4 weeks & $\begin{array}{c}3.92 \\
(0.27)\end{array}$ & $\begin{array}{c}1.31 \\
(0.25)\end{array}$ & $\begin{array}{l}9.45 \\
(0.02)\end{array}$ & $\begin{array}{c}0.83 \\
(0.36)\end{array}$ & $\begin{array}{l}0.41 \\
(0.94)\end{array}$ & $\begin{array}{c}0.02 \\
(0.89)\end{array}$ \\
\hline 8 weeks & $\begin{array}{l}4.57 \\
(0.21)\end{array}$ & $\begin{array}{l}2.55 \\
(0.11)\end{array}$ & $\begin{array}{l}8.44 \\
(0.04)\end{array}$ & $\begin{array}{c}0.52 \\
(0.47)\end{array}$ & $\begin{array}{l}2.67 \\
(0.45)\end{array}$ & $\begin{array}{l}1.20 \\
(0.27)\end{array}$ \\
\hline
\end{tabular}


Table 2: Brier's Score Tail Tests for Risk-Neutral Densities Estimated with a Mixture of Two Lognormals

October 1996-December 2004

Tests of misspecification for tails of estimated densities. For the right tail and the left tail, the frequency with which actual observations fall in those areas and the probability mass assigned by estimated RND are reported. The values of the ASN test statistic based on the Brier's score are also reported. The statistic is asymptotically distributed as a standard normal distribution.

\begin{tabular}{|c|c|c|c|c|c|c|c|c|c|}
\hline \multirow[b]{2}{*}{$\%$ Tails } & \multicolumn{3}{|c|}{ Oct. 1996-Dec. 2004} & \multicolumn{3}{|c|}{ Oct. 1996-Mar. 2000} & \multicolumn{3}{|c|}{ Apr. 2000-Dec. 2004} \\
\hline & Freq. & $\begin{array}{c}\text { Prob. } \\
\text { Forecast }\end{array}$ & ASN & Freq. & $\begin{array}{c}\text { Prob. } \\
\text { Forecast }\end{array}$ & ASN & Freq. & $\begin{array}{c}\text { Prob. } \\
\text { Forecast }\end{array}$ & ASN \\
\hline 1 week: & \multirow{3}{*}{0.05} & \multirow{3}{*}{0.08} & \multirow{3}{*}{-0.94} & \multirow{3}{*}{0.10} & \multirow{3}{*}{0.08} & \multirow{3}{*}{0.45} & \multirow{3}{*}{0.02} & \multirow{3}{*}{0.07} & \multirow[b]{2}{*}{-1.66} \\
\hline $\begin{array}{c}\text { Right Tail } \\
5 \%\end{array}$ & & & & & & & & & \\
\hline 1 week: & & & & & & & & & \\
\hline $\begin{array}{c}\text { Left Tail } \\
5 \%\end{array}$ & \multirow[t]{2}{*}{0.05} & \multirow[t]{2}{*}{0.09} & \multirow[t]{2}{*}{-1.42} & \multirow[t]{2}{*}{0.05} & \multirow[t]{2}{*}{0.09} & \multirow[t]{2}{*}{-1.01} & \multirow[t]{2}{*}{0.05} & \multirow[t]{2}{*}{0.08} & \multirow[t]{2}{*}{-1.00} \\
\hline 1 week: & & & & & & & & & \\
\hline $\begin{array}{c}\text { Both Tails } \\
5 \% \\
\end{array}$ & \multirow[t]{2}{*}{0.10} & \multirow[t]{2}{*}{0.16} & \multirow[t]{2}{*}{-1.80} & \multirow[t]{2}{*}{0.14} & \multirow[t]{2}{*}{0.17} & \multirow[t]{2}{*}{-0.50} & \multirow[t]{2}{*}{0.07} & \multirow[t]{2}{*}{0.16} & \multirow[t]{2}{*}{-2.00} \\
\hline 4 weeks: & & & & & & & & & \\
\hline $\begin{array}{c}\text { Right Tail } \\
10 \% \\
\end{array}$ & \multirow[t]{2}{*}{0.12} & \multirow[t]{2}{*}{0.07} & \multirow[t]{2}{*}{2.06} & \multirow[t]{2}{*}{0.22} & 0.08 & 3.61 & 0.05 & 0.06 & -0.54 \\
\hline 4 weeks: & & & & & & & & & \\
\hline $\begin{array}{c}\text { Left Tail } \\
10 \% \\
\end{array}$ & 0.05 & 0.09 & -1.29 & 0.05 & 0.10 & -1.16 & 0.05 & 0.08 & -0.68 \\
\hline 4 weeks: & & & & & & & & & \\
\hline $\begin{array}{c}\text { Both Tails } \\
10 \% \\
\end{array}$ & 0.17 & 0.16 & 0.38 & 0.27 & 0.18 & 1.58 & 0.11 & 0.14 & -0.88 \\
\hline 8 weeks: & & & & & & & & & \\
\hline $\begin{array}{c}\text { Right Tail } \\
10 \% \\
\end{array}$ & 0.14 & 0.14 & 0.38 & 0.30 & 0.16 & 2.15 & 0.03 & 0.13 & -1.34 \\
\hline 8 weeks: & & & & & & & & & \\
\hline $\begin{array}{c}\text { Left Tail } \\
10 \% \\
\end{array}$ & 0.10 & 0.15 & -0.91 & 0.05 & 0.16 & -1.48 & 0.14 & 0.14 & 0.05 \\
\hline $\begin{array}{c}8 \text { weeks: } \\
\text { Both Tails } \\
10 \% \\
\end{array}$ & 0.24 & 0.29 & 0.12 & 0.35 & 0.32 & 0.99 & 0.17 & 0.26 & -0.57 \\
\hline
\end{tabular}


Table 3: Estimated Parameters from Alternative Specifications for the Projected Stochastic Discount Factor and Estimates of Risk Aversion

Values of risk aversion parameters obtained by maximizing the forecasting ability of the risk-adjusted PDFs measured using the Berkowitz statistic.

\begin{tabular}{|c|c|c|c|c|}
\hline \multicolumn{5}{|c|}{$\begin{array}{l}\text { Panel A: Estimated Parameters from Alternative Specifications } \\
\text { for the Projected Stochastic Discount Factor }\end{array}$} \\
\hline \multicolumn{2}{|r|}{ Power } & \multicolumn{3}{|c|}{ Exponential } \\
\hline Horizon & $\gamma$ & \multicolumn{3}{|c|}{$\gamma$} \\
\hline 1 week & \multicolumn{2}{|l|}{3.54} & \multicolumn{2}{|c|}{0.000421} \\
\hline 4 weeks & \multicolumn{2}{|l|}{1.70} & \multicolumn{2}{|c|}{0.000197} \\
\hline 8 weeks & \multicolumn{2}{|l|}{1.67} & \multicolumn{2}{|c|}{0.000184} \\
\hline \multicolumn{5}{|c|}{ Panel B: Projected Risk Aversion Estimates } \\
\hline & Power & \multicolumn{3}{|c|}{ Exponential } \\
\hline Horizon & \multirow[b]{2}{*}{3.54} & Range (a) & Mean & Median \\
\hline 1 week & & $1.84-5.23$ & 3.50 & 3.47 \\
\hline 4 weeks & \multirow{2}{*}{$\begin{array}{l}1.70 \\
1.67\end{array}$} & $0.88-2.45$ & 1.64 & 1.62 \\
\hline 8 weeks & & $0.92-2.28$ & 1.54 & 1.52 \\
\hline
\end{tabular}

a. Risk aversion estimates over the whole sample 
Table 4: Berkowitz Tests for Power- and Exponential-Adjusted Densities Estimated with a Mixture of Two Lognormals

October 1996-December 2004

The reported LR value is the Berkowitz likelihood ratio test for i.i.d. normality of the inverse-normal transformed inverse probability transforms of the realizations as given by $L R=-2[L(0,1,0)-L(\mu, \sigma, \rho)]$ which is distributed as a $\chi^{2}(3)$. The $L R(i)$ statistic is the Berkowitz likelihood ratio test for independence. Rejection of the test for independence suggests that rejection of the density as a good forecast may be due to serial correlation rather than poor forecasting performance.

\begin{tabular}{|c|c|c|c|c|c|c|}
\hline \multicolumn{7}{|c|}{ Panel A: Power Specification } \\
\hline \multirow{2}{*}{$\begin{array}{c}\text { Forecast } \\
\text { Horizon }\end{array}$} & \multicolumn{2}{|c|}{ Oct. 1996-Dec. 2004} & \multicolumn{2}{|c|}{ Oct. 1996-Mar. 2000} & \multicolumn{2}{|c|}{ Apr. 2000-Dec. 2004} \\
\hline & $\begin{array}{c}\text { LR } \\
\text { (p-value) }\end{array}$ & $\begin{array}{c}\mathrm{LR}(\mathrm{i}) \\
(\mathrm{p}- \\
\text { value })\end{array}$ & $\begin{array}{c}\text { LR } \\
\text { (p-value) }\end{array}$ & $\begin{array}{c}\text { LR(i) } \\
(p- \\
\text { value) }\end{array}$ & $\begin{array}{c}\text { LR } \\
\text { (p-value }\end{array}$ & $\begin{array}{c}\text { LR(i) } \\
\text { (p-value) }\end{array}$ \\
\hline 1 week & $\begin{array}{l}2.99 \\
(0.39)\end{array}$ & $\begin{array}{l}1.00 \\
(0.32)\end{array}$ & $\begin{array}{l}1.78 \\
(0.62)\end{array}$ & $\begin{array}{l}0.35 \\
(0.55)\end{array}$ & $\begin{array}{l}12.49 \\
(0.01)\end{array}$ & $\begin{array}{l}0.41 \\
(0.59)\end{array}$ \\
\hline 4 weeks & $\begin{array}{l}2.43 \\
(0.49)\end{array}$ & $\begin{array}{l}1.74 \\
(0.19)\end{array}$ & $\begin{array}{c}6.06 \\
(0.11)\end{array}$ & $\begin{array}{l}1.05 \\
(0.31)\end{array}$ & $\begin{array}{l}1.83 \\
(0.61)\end{array}$ & $\begin{array}{l}0.01 \\
(0.94)\end{array}$ \\
\hline 8 weeks & $\begin{array}{l}3.15 \\
(0.37)\end{array}$ & $\begin{array}{l}2.61 \\
(0.11)\end{array}$ & $\begin{array}{l}5.46 \\
(0.14)\end{array}$ & $\begin{array}{l}0.55 \\
(0.46)\end{array}$ & $\begin{array}{l}4.16 \\
(0.24)\end{array}$ & $\begin{array}{c}1.64 \\
(0.20)\end{array}$ \\
\hline \multicolumn{7}{|c|}{ Panel B: Exponential Specification } \\
\hline \multirow{2}{*}{$\begin{array}{c}\text { Forecast } \\
\text { Horizon }\end{array}$} & \multicolumn{2}{|c|}{ Oct. 1996-Dec. 2004} & \multicolumn{2}{|c|}{ Oct. 1996-Mar. 2000} & \multicolumn{2}{|c|}{ Apr. 2000-Dec. 2004} \\
\hline & $\begin{array}{c}\text { LR } \\
\text { (p-value) }\end{array}$ & $\begin{array}{c}\mathrm{LR}(\mathrm{i}) \\
\text { (p-value) }\end{array}$ & $\begin{array}{c}\text { LR } \\
\text { (p-value) }\end{array}$ & $\begin{array}{c}\text { LR(i) } \\
\text { (p-value) }\end{array}$ & $\begin{array}{c}\text { LR } \\
\text { (p-value) }\end{array}$ & $\begin{array}{c}\text { LR(i) } \\
\text { (p-value) }\end{array}$ \\
\hline 1 week & $\begin{array}{l}3.00 \\
(0.39)\end{array}$ & $\begin{array}{l}1.19 \\
(0.28)\end{array}$ & $\begin{array}{l}1.99 \\
(0.58)\end{array}$ & $\begin{array}{c}0.44 \\
(0.51)\end{array}$ & $\begin{array}{l}12.42 \\
(0.01)\end{array}$ & $\begin{array}{c}0.52 \\
(0.47)\end{array}$ \\
\hline 4 weeks & $\begin{array}{l}2.51 \\
(0.47)\end{array}$ & $\begin{array}{l}1.76 \\
(0.18)\end{array}$ & $\begin{array}{l}6.21 \\
(0.10)\end{array}$ & $\begin{array}{l}1.13 \\
(0.29)\end{array}$ & $\begin{array}{l}1.67 \\
(0.64)\end{array}$ & $\begin{array}{l}0.00 \\
(0.95)\end{array}$ \\
\hline 8 weeks & $\begin{array}{l}3.33 \\
(0.34)\end{array}$ & $\begin{array}{l}2.72 \\
(0.1)\end{array}$ & $\begin{array}{l}5.77 \\
(0.12)\end{array}$ & $\begin{array}{l}0.61 \\
(0.43)\end{array}$ & $\begin{array}{l}3.96 \\
(0.27)\end{array}$ & $\begin{array}{l}1.68 \\
(0.20)\end{array}$ \\
\hline
\end{tabular}


Table 5: Brier's Score Tail Tests for Power- and Exponential-Adjusted Densities Estimated with a Mixture of Two Lognormals October 1996-December 2004

Tests of misspecification for tails of estimated densities. For the right tail and the left tail, the frequency with which actual observations fall in those areas and the probability mass assigned by estimated risk-adjusted densities are reported. The values of the ASN test statistic based on the Brier's score are also reported. The statistic is asymptotically distributed as a standard normal distribution.

\begin{tabular}{|c|c|c|c|c|c|c|c|c|c|}
\hline \multicolumn{10}{|c|}{ Panel A: Power Specification } \\
\hline \multirow[b]{2}{*}{$\%$ Tails } & \multicolumn{3}{|c|}{ Oct. 1996-Dec. 2004} & \multicolumn{3}{|c|}{ Oct. 1996-Mar. 2000} & \multicolumn{3}{|c|}{ Apr. 2000-Dec. 2004} \\
\hline & Freq. & $\begin{array}{c}\text { Prob. } \\
\text { Forecast (a) }\end{array}$ & ASN & Freq. & $\begin{array}{c}\text { Prob. } \\
\text { Forecast }\end{array}$ & ASN & Freq. & $\begin{array}{c}\text { Prob. } \\
\text { Forecast }\end{array}$ & ASN \\
\hline 1 week: & & & & & & & & & \\
\hline $\begin{array}{c}\text { Right Tail } \\
5 \% \\
\end{array}$ & 0.05 & 0.10 & -1.48 & 0.10 & 0.10 & -0.02 & 0.02 & 0.09 & -1.97 \\
\hline 1 week: & & & & & & & & & \\
\hline $\begin{array}{l}\text { Left Tail } \\
5 \%\end{array}$ & 0.05 & 0.06 & -0.68 & 0.05 & 0.07 & -0.56 & 0.05 & 0.06 & -0.41 \\
\hline $\begin{array}{c}1 \text { week: } \\
\text { Both Tails } \\
5 \%\end{array}$ & 0.10 & 0.16 & -1.74 & 0.14 & 0.16 & -0.43 & 0.07 & 0.16 & -1.98 \\
\hline 4 weeks: & & & & & & & & & \\
\hline $\begin{array}{c}\text { Right Tail } \\
10 \% \\
\end{array}$ & 0.12 & 0.09 & 1.26 & 0.22 & 0.10 & 2.93 & 0.05 & 0.08 & -0.98 \\
\hline $\begin{array}{c}4 \text { weeks: } \\
\text { Left Tail } \\
10 \%\end{array}$ & 0.05 & 0.07 & -0.61 & 0.05 & 0.08 & -0.69 & 0.05 & 0.06 & -0.19 \\
\hline $\begin{array}{c}4 \text { weeks: } \\
\text { Both Tails } \\
10 \%\end{array}$ & 0.17 & 0.15 & 0.57 & 0.27 & 0.17 & 1.75 & 0.11 & 0.14 & -0.79 \\
\hline 8 weeks: & & & & & & & & & \\
\hline $\begin{array}{c}\text { Right Tail } \\
10 \% \\
\end{array}$ & 0.14 & 0.18 & -0.15 & 0.30 & 0.20 & 1.70 & 0.03 & 0.16 & -1.60 \\
\hline $\begin{array}{c}8 \text { weeks: } \\
\text { Left Tail } \\
10 \%\end{array}$ & 0.10 & 0.11 & -0.11 & 0.05 & 0.12 & -1.00 & 0.14 & 0.10 & 0.71 \\
\hline $\begin{array}{c}8 \text { weeks: } \\
\text { Both Tails } \\
10 \%\end{array}$ & 0.24 & 0.28 & 0.22 & 0.35 & 0.32 & 1.05 & 0.17 & 0.26 & -0.50 \\
\hline
\end{tabular}

a. The probability forecast is obtained as the average of probabilities from the estimated densities 
Table 5: Brier's Score Tail Tests for Power- and Exponential-Adjusted Densities

Estimated with a Mixture of Two Lognormals (Cont'd)

October 1996-December 2004

Tests of misspecification for tails of estimated densities. For the right tail and the left tail, the frequency with which actual observations fall in those areas and the probability mass assigned by estimated risk-adjusted densities are reported. The values of the ASN test statistic based on the Brier's score are also reported. The statistic is asymptotically distributed as a standard normal distribution.

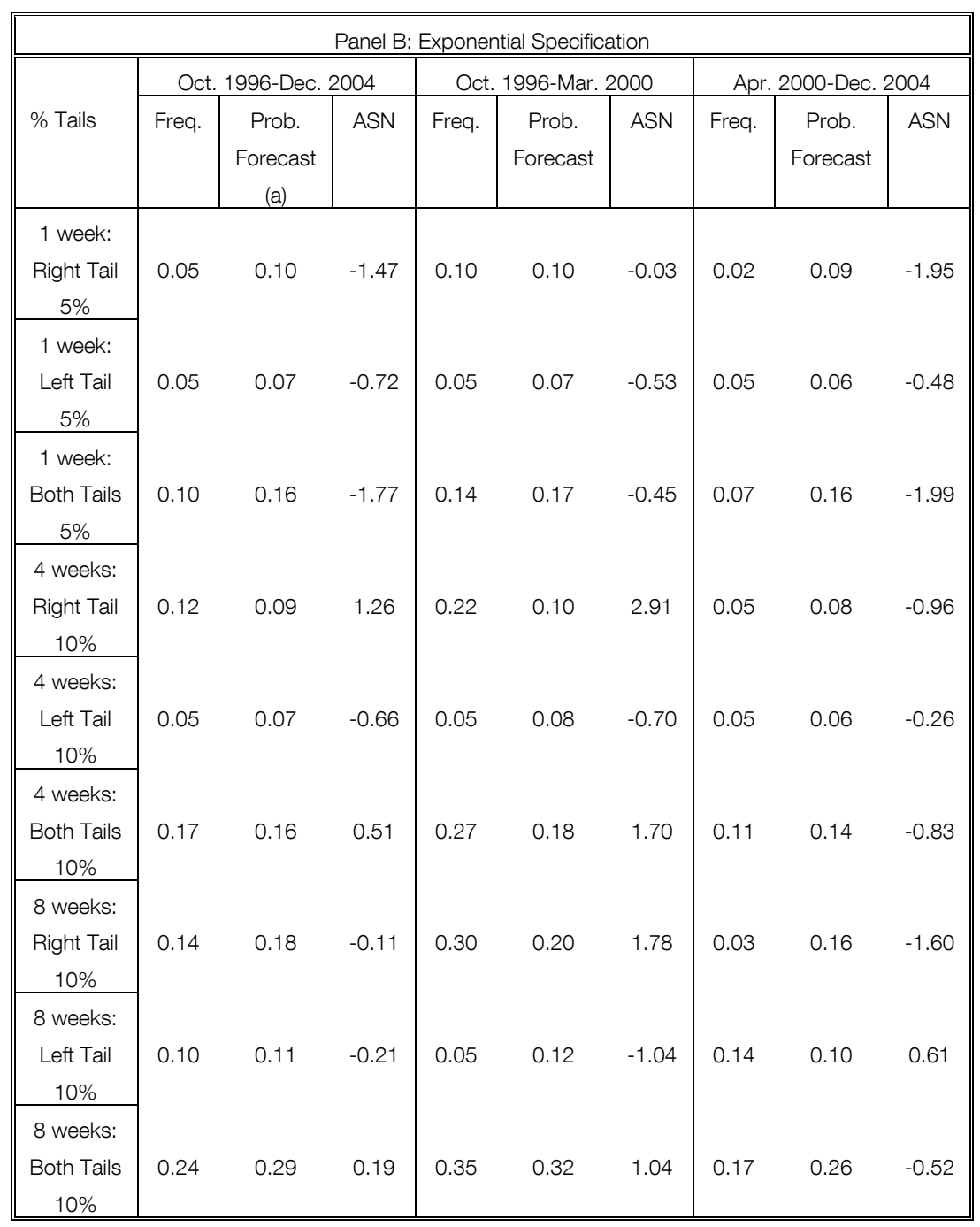

a. The probability forecast is obtained as the average of probabilities from the estimated densities 
Table 6: Estimates of Risk Aversion from Alternative Specifications for the Projected Stochastic Discount Factor and Periods of High and Low at-the-money Implied Volatility

\section{October 1996-December 2004}

Values of risk aversion parameters obtained by maximizing the forecasting ability of the risk-adjusted PDFs measured using the Berkowitz statistic. The high and low at-the-money volatility results are obtained by first dividing the whole sample in two equal halves which includes the highest and lowest levels of at-the-money implied volatility, and then re-estimating the Berkowitz maximizing values of risk aversion for each sub-sample.

\begin{tabular}{|c|c|c|c|c|}
\hline \multicolumn{5}{|c|}{ Panel A: Risk Aversion Estimates. High volatility } \\
\hline & Power & \multicolumn{3}{|c|}{ Exponential } \\
\hline Horizon & \multirow{4}{*}{$\begin{array}{l}0.59 \\
0.91 \\
0.49 \\
\end{array}$} & Range (a) & Mean & Median \\
\hline 1 week & & $0.50-1.08$ & 0.74 & 0.74 \\
\hline 4 weeks & & $0.65-1.40$ & 0.96 & 0.95 \\
\hline 8 weeks & & $0.03-0.64$ & 0.45 & 0.48 \\
\hline \multicolumn{5}{|c|}{ Panel B: Risk Aversion Estimates. Low volatility } \\
\hline & Power & \multicolumn{3}{|c|}{ Exponential } \\
\hline Horizon & & Range (a) & Mean & Median \\
\hline 1 week & 8.50 & $4.36-11.46$ & 8.06 & 8.12 \\
\hline 4 weeks & 3.17 & $1.47-3.82$ & 2.67 & 2.66 \\
\hline 8 weeks & 4.09 & $2.30-5.36$ & 3.71 & 3.67 \\
\hline
\end{tabular}

a. Risk aversion estimates over the whole sample. 
Table 7: Berkowitz Tests for Power, Habit and Time-varying Risk Aversion Adjusted Densities Estimated with a Mixture of Two Lognormals and a Four-week Horizon October 1996-December 2004

The reported $L R$ value is the Berkowitz likelihood ratio test for i.i.d. normality of the inverse-normal transformed inverse probability transforms of the realizations as given by $L R=-2[L(0,1,0)-L(\mu, \sigma, \rho)]$ which is distributed as a $\chi^{2}(3)$. The $L R(i)$ statistic is the Berkowitz likelihood ratio test for independence. Rejection of the test for independence suggests that rejection of the density as a good forecast may be due to serial correlation rather than poor forecasting performance. The stochastic discount factors for each model are given by: $m\left(P_{t+\tau}\right)=P_{t+\tau}^{-\gamma}$ (power); $m\left(P_{t+\tau}\right)=\left(P_{t+\tau}-H_{t+\tau}\right)^{-\gamma}$ (habit); $m\left(P_{t+\tau}\right)=P_{t+\tau}^{\gamma t+\tau}$ (model 1, with $\left.\gamma_{t+\tau}=\gamma\left(P_{t}, \cdots, P_{t-L}\right)\right) ; m\left(P_{t+\tau}\right)=P_{t+\tau}^{\gamma t+\tau}$ (model 2, with $\left.\gamma_{t+\tau}=\alpha I V_{t}^{\eta}\right)$, where $H$ is the level of habit and $I$ is implied volatility.

\begin{tabular}{|c|c|c|c|c|c|c|}
\hline \multirow{2}{*}{ Model } & \multicolumn{2}{|c|}{ Oct. 1996-Dec. 2004} & \multicolumn{2}{|c|}{ Oct. 1996-Mar. 2000} & \multicolumn{2}{|c|}{ Apr. 2000-Dec. 2004} \\
\hline & $\begin{array}{c}\text { LR } \\
\text { (p-value) }\end{array}$ & $\begin{array}{c}\mathrm{LR}(\mathrm{i}) \\
\text { (p-value) }\end{array}$ & $\begin{array}{c}\text { LR } \\
\text { (p-value) }\end{array}$ & $\begin{array}{c}\text { LR(i) } \\
\text { (p-value) }\end{array}$ & $\begin{array}{c}\text { LR } \\
\text { (p-value) }\end{array}$ & $\begin{array}{c}\mathrm{LR}(\mathrm{i}) \\
\text { (p-value) }\end{array}$ \\
\hline Power & $\begin{array}{l}2.43 \\
(0.49)\end{array}$ & $\begin{array}{c}1.74 \\
(0.19)\end{array}$ & $\begin{array}{l}6.06 \\
(0.11)\end{array}$ & $\begin{array}{l}1.05 \\
(0.31)\end{array}$ & $\begin{array}{l}1.83 \\
(0.61)\end{array}$ & $\begin{array}{l}0.01 \\
(0.94)\end{array}$ \\
\hline Habit & $\begin{array}{l}2.38 \\
(0.50)\end{array}$ & $\begin{array}{c}1.71 \\
(0.19)\end{array}$ & $\begin{array}{l}5.98 \\
(0.11)\end{array}$ & $\begin{array}{l}1.04 \\
(0.31)\end{array}$ & $\begin{array}{l}1.86 \\
(0.60)\end{array}$ & $\begin{array}{c}0.00 \\
(0.95)\end{array}$ \\
\hline Model 1 & 2.34 & 1.67 & 5.88 & 1.04 & 1.85 & 0.00 \\
\hline & $(0.50)$ & $(0.20)$ & $(0.12)$ & $(0.31)$ & $(0.61)$ & (0.95) \\
\hline Model $2(\eta=-1)$ & $\begin{array}{l}1.87 \\
(0.60)\end{array}$ & $\begin{array}{c}1.28 \\
(0.26)\end{array}$ & $\begin{array}{l}5.33 \\
(0.15)\end{array}$ & $\begin{array}{c}0.81 \\
(0.37)\end{array}$ & $\begin{array}{c}2.47 \\
(0.48)\end{array}$ & $\begin{array}{c}0.01 \\
(0.90)\end{array}$ \\
\hline Model $2(\boldsymbol{\eta}=-2)$ & $\begin{array}{l}1.30 \\
(0.73)\end{array}$ & $\begin{array}{c}0.80 \\
(0.37)\end{array}$ & $\begin{array}{l}4.89 \\
(0.18)\end{array}$ & $\begin{array}{c}0.59 \\
(0.44)\end{array}$ & $\begin{array}{l}3.28 \\
(0.35)\end{array}$ & $\begin{array}{l}0.17 \\
(0.68)\end{array}$ \\
\hline
\end{tabular}




\section{October 1996-December 2004}

For each model, the risk premium is estimated as the difference between the mean of the risk-adjusted PDF and the mean of the RND, normalized by the mean of the RND. The last line reports the annualized average risk-premium as the required compensation for an investor with the sample average risk aversion under power utility, $\gamma=1.70$, and realised market volatility of $24.5 \%$. The maximum risk-premium is obtained for the month with the highest realised volatility of $72.8 \%$ and $\gamma=0.91$; the minimum risk-premium is obtained for the month with the lowest realised volatility of $10.4 \%$ and $\gamma=3.17$.

The stochastic discount factors for each model are given by: $m\left(P_{t+\tau}\right)=P_{t+\tau}^{-\gamma}$ (power); $\quad m\left(P_{t+\tau}\right)=\left(P_{t+\tau}-H_{t+\tau}\right)^{-\gamma}$ (habit); $\quad m\left(P_{t+\tau}\right)=P_{t+\tau}^{\gamma t+\tau}$ (model 1, with $\left.\gamma_{t+\tau}=\gamma\left(P_{t}, \cdots, P_{t-L}\right)\right) ; m\left(P_{t+\tau}\right)=P_{t+\tau}^{\gamma t+\tau}$ (model 2, with $\left.\gamma_{t+\tau}=\alpha I V_{t}^{\eta}\right)$, where $H$ is the level of habit and $I$ is implied volatility.

\begin{tabular}{|c|c|c|c|}
\hline \multirow[b]{2}{*}{ Model } & \multicolumn{3}{|c|}{ October 1996-December 2004} \\
\hline & $\begin{array}{c}\text { Average } \\
\text { Risk-Premium } \\
\text { (Annualized in \%) }\end{array}$ & $\begin{array}{c}\text { Max } \\
\text { Risk-Premium }\end{array}$ & $\begin{array}{c}\text { Min } \\
\text { Risk-Premium }\end{array}$ \\
\hline Power & 11.52 & 44.30 & 1.96 \\
\hline Habit & 11.66 & 42.89 & 2.03 \\
\hline Model 1 & 11.81 & 43.91 & 2.06 \\
\hline Model $2(\eta=-1)$ & 12.45 & 26.33 & 5.39 \\
\hline Model $2(\boldsymbol{\eta}=-2)$ & 12.37 & 13.19 & 11.77 \\
\hline $\begin{array}{c}\text { Investor with sample } \\
\text { average relative risk } \\
\text { aversion and realised } \\
\text { market volatility }\end{array}$ & 10.19 & 48.27 & 3.40 \\
\hline
\end{tabular}


Figure 1: Estimated PDFs for Selected Trading Days. Four-week Horizon
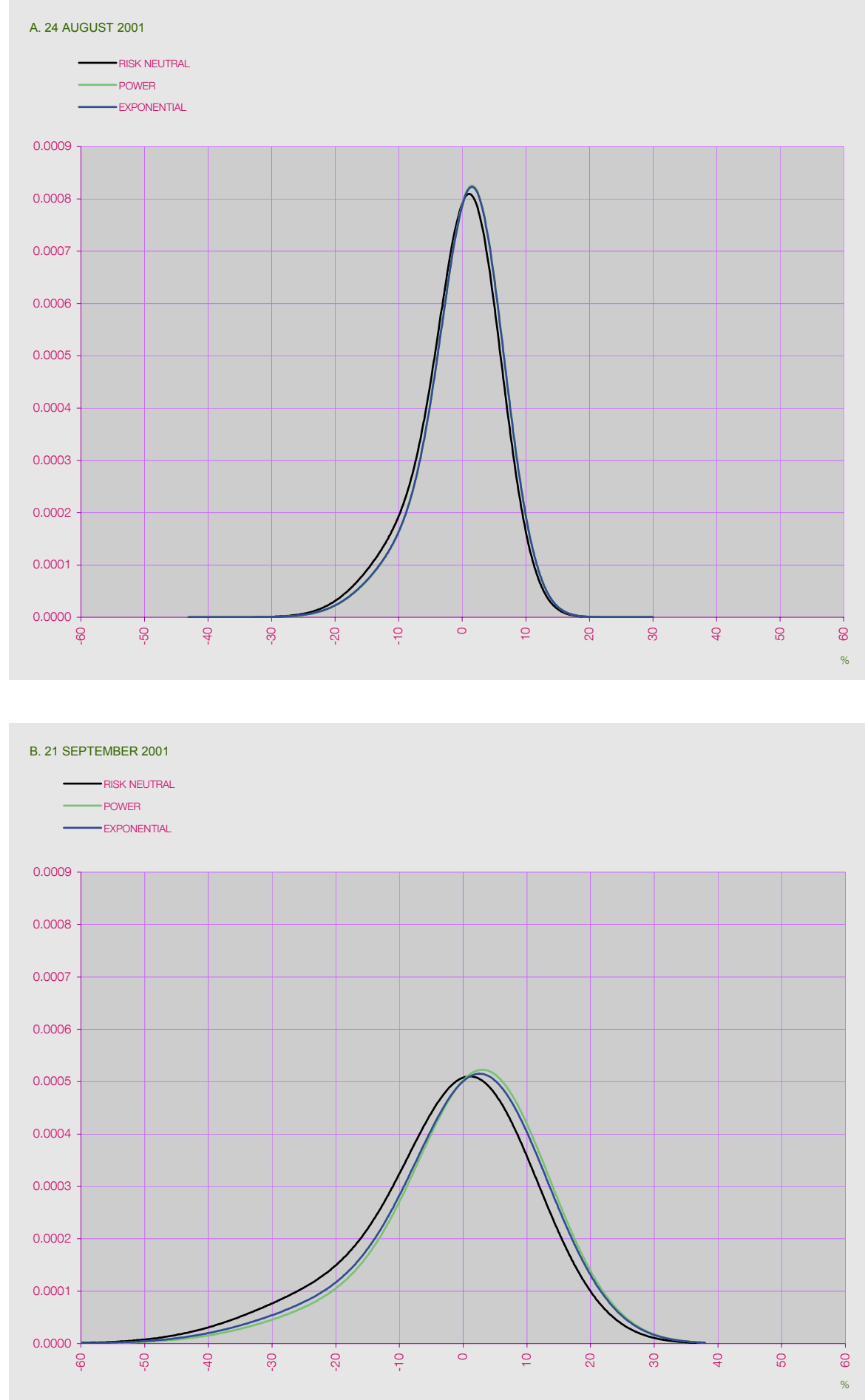
Figure 2: Estimated Risk Premium (a). Four-week Horizon

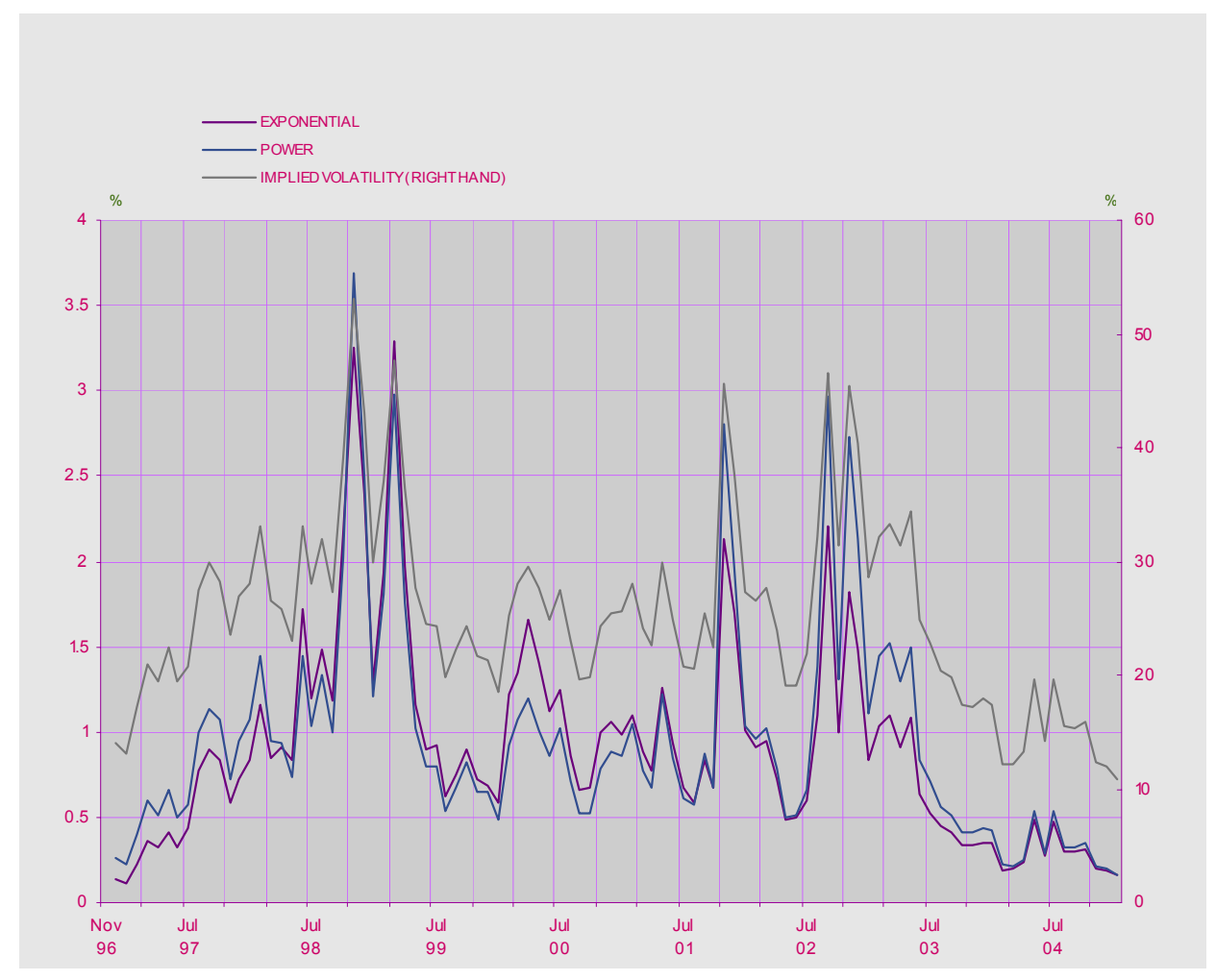

a. Risk premium estimated as the difference between the mean of the riskadjusted PDF and the mean of the RND, normalized by the mean of the RND. 
Figure 3: Estimated Risk Premium (a) with High and Low Volatility.

Four-week Horizon

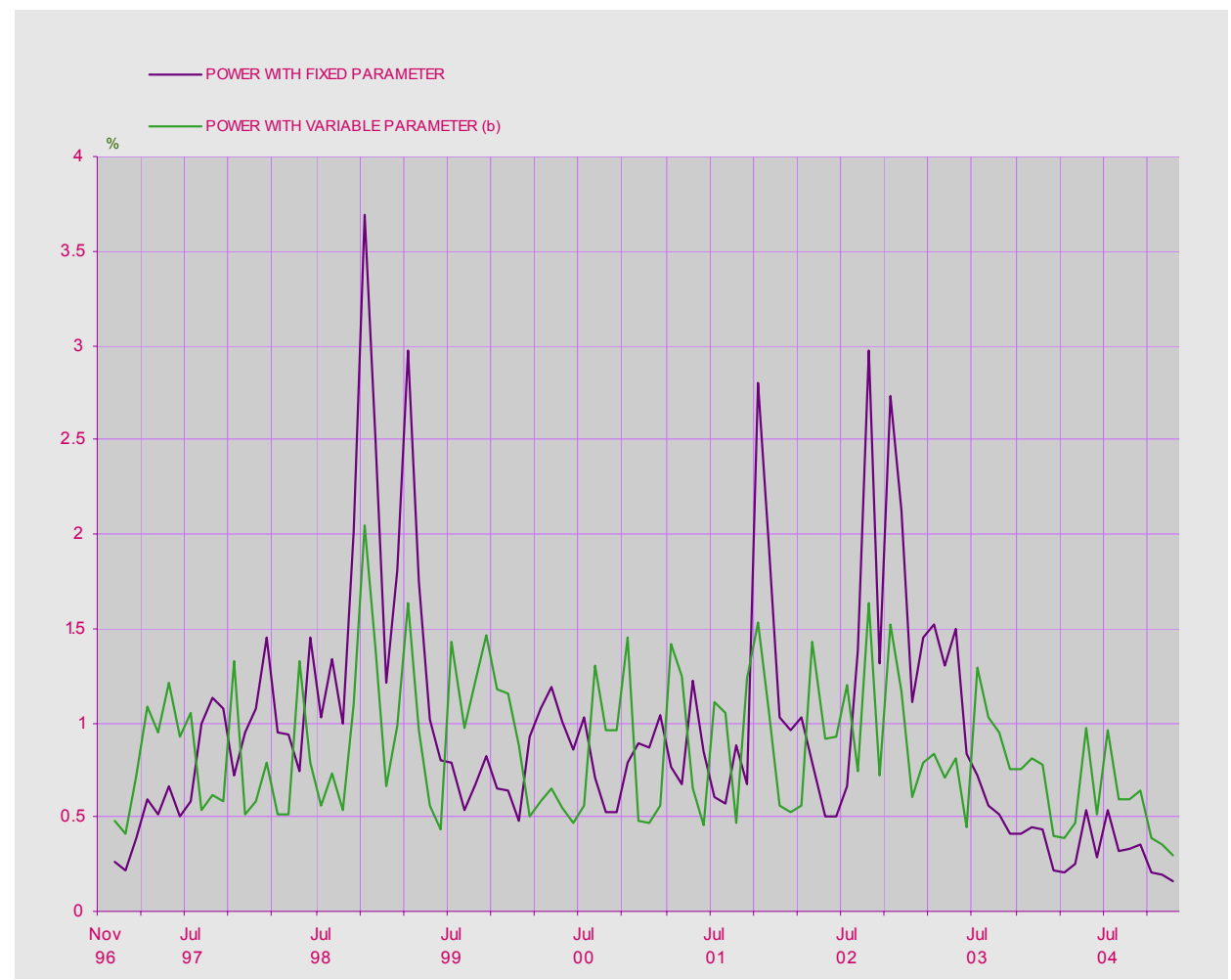

a. Risk premium estimated as the difference between the mean of the riskadjusted PDF and the mean of the RND, normalized by the mean of the RND.

b. Gamma takes two alternative values depending on at-the-money implied volatility. 
Figure 4: Estimated Risk Premium (a) with Alternative Models for the Projected Stochastic Discount Factor. Four-week Horizon

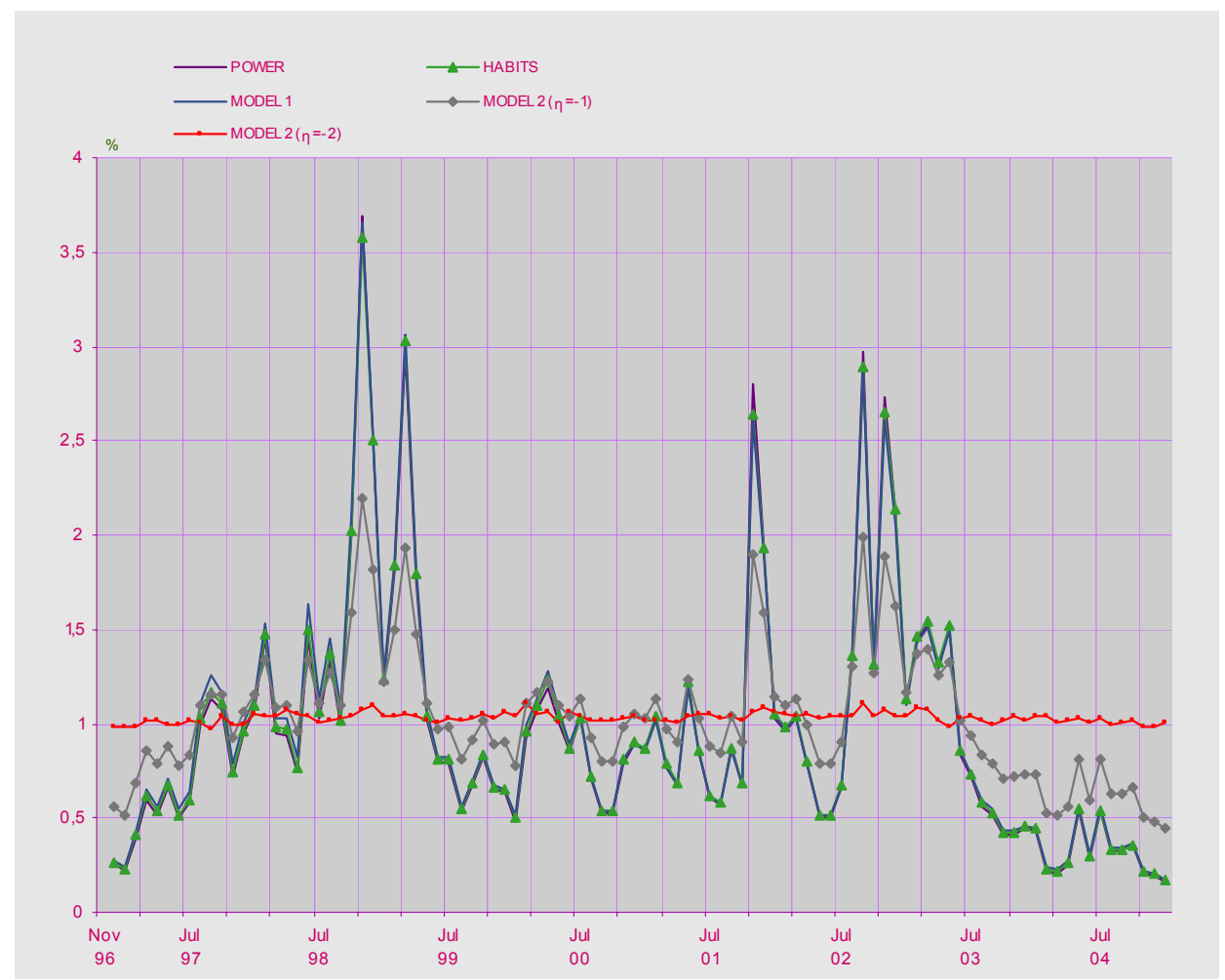

a. Risk premium estimated as the difference between the mean of the risk-adjusted PDF and the mean of the RND, normalized by the mean of the RND. 

BANCO DE ESPAÑA PUBLICATIONS

\section{WORKING PAPERS ${ }^{1}$}

0527 LUIS J. ÁLVAREZ, PABLO BURRIEL AND IGNACIO HERNANDO: Price setting behaviour in Spain: evidence from micro PPI data.

0528 EMMANUEL DHYNE, LUIS J. ÁLVAREZ, HERVÉ LE BIHAN, GIOVANNI VERONESE, DANIEL DIAS, JOHANNES HOFFMANN, NICOLE JONKER, PATRICK LÜNNEMANN, FABIO RUMLER AND JOUKO VILMUNEN: Price setting in the euro area: some stylized facts from individual consumer price data.

0529 TERESA SASTRE AND JOSÉ LUIS FERNÁNDEZ-SÁNCHEZ: Un modelo empírico de las decisiones de gasto de las familias españolas.

0530 ALFREDO MARTÍN-OLIVER, VICENTE SALAS-FUMÁS AND JESÚS SAURINA: A test of the law of one price in retail banking.

0531 GABRIEL JIMÉNEZ AND JESÚS SAURINA: Credit cycles, credit risk, and prudential regulation.

0532 BEATRIZ DE-BLAS-PÉREZ: Exchange rate dynamics in economies with portfolio rigidities.

0533 ÓSCAR J. ARCE: Reflections on fiscalist divergent price-paths.

0534 M. ${ }^{a}$ DE LOS LLANOS MATEA AND MIGUEL PÉREZ: Differences in changes in fresh food prices by type of establishment. (The Spanish original of this publication has the same number.)

0535 JOSÉ MANUEL MARQUÉS, FERNANDO NIETO AND ANA DEL RíO: Una aproximación a los determinantes de la financiación de las sociedades no financieras en España.

0536 S. FABIANI, M. DRUANT, I. HERNANDO, C. KWAPIL, B. LANDAU, C. LOUPIAS, F. MARTINS, T. MATHÄ, R. SABBATINI, H. STAHL AND A. STOKMAN: The pricing behaviour of firms in the euro area: new survey evidence.

0537 LUIS J. ÁLVAREZ AND I. HERNANDO: The price setting behaviour of Spanish firms: evidence from survey data.

0538 JOSÉ MANUEL CAMPA, LINDA S. GOLDBERG AND JOSÉ M. GONZÁLEZ-MíNGUEZ: Exchange-rate pass-through to import prices in the euro area.

0539 RAQUEL LAGO-GONZÁLEZ AND VICENTE SALAS-FUMÁS: Market power and bank interest rate adjustments.

0540 FERNANDO RESTOY AND ROSA RODRÍGUEZ: Can fundamentals explain cross-country correlations of asset returns?

0541 FRANCISCO ALONSO AND ROBERTO BLANCO: Is the volatility of the EONIA transmitted to longer-term euro money market interest rates?

0542 LUIS J. ÁLVAREZ, EMMANUEL DHYNE, MARCO M. HOEBERICHTS, CLAUDIA KWAPIL, HERVÉ LE BIHAN, PATRICK LÜNNEMANN, FERNANDO MARTINS, ROBERTO SABBATINI, HARALD STAHL, PHILIP VERMEULEN AND JOUKO VILMUNEN: Sticky prices in the euro area: a summary of new micro evidence.

0601 ARTURO GALINDO, ALEJANDRO IZQUIERDO AND JOSÉ MANUEL MONTERO: Real exchange rates, dollarization and industrial employment in Latin America.

0602 JUAN A. ROJAS AND CARLOS URRUTIA: Social security reform with uninsurable income risk and endogenous borrowing constraints.

0603 CRISTINA BARCELÓ: Housing tenure and labour mobility: a comparison across European countries.

0604 FRANCISCO DE CASTRO AND PABLO HERNÁNDEZ DE COS: The economic effects of exogenous fiscal shocks in Spain: a SVAR approach.

0605 RICARDO GIMENO AND CARMEN MARTÍNEZ-CARRASCAL: The interaction between house prices and loans for house purchase. The Spanish case.

0606 JAVIER DELGADO, VICENTE SALAS AND JESÚS SAURINA: The joint size and ownership specialization in banks' lending.

0607 ÓSCAR J. ARCE: Speculative hyperinflations: When can we rule them out?

0608 PALOMA LÓPEZ-GARCÍA AND SERGIO PUENTE: Business demography in Spain: determinants of firm survival.

0609 JUAN AYUSO AND FERNANDO RESTOY: House prices and rents in Spain: Does the discount factor matter?

0610 ÓSCAR J. ARCE AND J. DAVID LÓPEZ-SALIDO: House prices, rents, and interest rates under collateral constraints.

0611 ENRIQUE ALBEROLA AND JOSÉ MANUEL MONTERO: Debt sustainability and procyclical fiscal policies in Latin America.

1. Previously published Working Papers are listed in the Banco de España publications calalogue. 
0612 GABRIEL JIMÉNEZ, VICENTE SALAS AND JESÚS SAURINA: Credit market competition, collateral and firms' finance.

0613 ÁNGEL GAVILÁN: Wage inequality, segregation by skill and the price of capital in an assignment model.

0614 DANIEL PÉREZ, VICENTE SALAS AND JESÚS SAURINA: Earnings and capital management in alternative loan loss provision regulatory regimes.

0615 MARIO IZQUIERDO AND AITOR LACUESTA: Wage inequality in Spain: Recent developments.

0616 K. C. FUNG, ALICIA GARCÍA-HERRERO, HITOMI IIZAKA AND ALAN SUI: Hard or soft? Institutional reforms and infraestructure spending as determinants of foreign direct investment in China.

0617 JAVIER DÍAZ-CASSOU, ALICIA GARCÍA-HERRERO AND LUIS MOLINA: What kind of capital flows does the IMF catalyze and when?

0618 SERGIO PUENTE: Dynamic stability in repeated games.

0619 FEDERICO RAVENNA: Vector autoregressions and reduced form representations of DSGE models.

0620 AITOR LACUESTA: Emigration and human capital: Who leaves, who comes back and what difference does it make?

0621 ENRIQUE ALBEROLA AND RODRIGO CÉSAR SALVADO: Banks, remittances and financial deepening in receiving countries. A model.

0622 SONIA RUANO-PARDO AND VICENTE SALAS-FUMÁS: Morosidad de la deuda empresarial bancaria en España, 1992-2003. Modelos de la probabilidad de entrar en mora, del volumen de deuda en mora y del total de deuda bancaria, a partir de datos individuales de empresa.

0623 JUAN AYUSO AND JORGE MARTÍNEZ: Assessing banking competition: an application to the Spanish market for (quality-changing) deposits.

0624 IGNACIO HERNANDO AND MARÍA J. NIETO: Is the Internet delivery channel changing banks' performance? The case of Spanish banks.

0625 JUAN F. JIMENO, ESTHER MORAL AND LORENA SAIZ: Structural breaks in labor productivity growth: The United States vs. the European Union.

0626 CRISTINA BARCELÓ: A Q-model of labour demand.

0627 JOSEP M. VILARRUBIA: Neighborhood effects in economic growth.

0628 NUNO MARTINS AND ERNESTO VILLANUEVA: Does limited access to mortgage debt explain why young adults live with their parents?

0629 LUIS J. ÁLVAREZ AND IGNACIO HERNANDO: Competition and price adjustment in the euro area.

0630 FRANCISCO ALONSO, ROBERTO BLANCO AND GONZALO RUBIO: Option-implied preferences adjustments, density forecast, and the equity risk premium.

\begin{tabular}{|c|c|}
\hline BANCODEESPAÑ & $\begin{array}{c}\text { Unidad de Publicaciones } \\
\text { Alcalá, 522; } 28027 \text { Madrid } \\
\text { Telephone +34 } 913386363 \text {. Fax +34 } 913386488 \\
\text { e-mail: Publicaciones@bde.es } \\
\text { www.bde.es }\end{array}$ \\
\hline
\end{tabular}




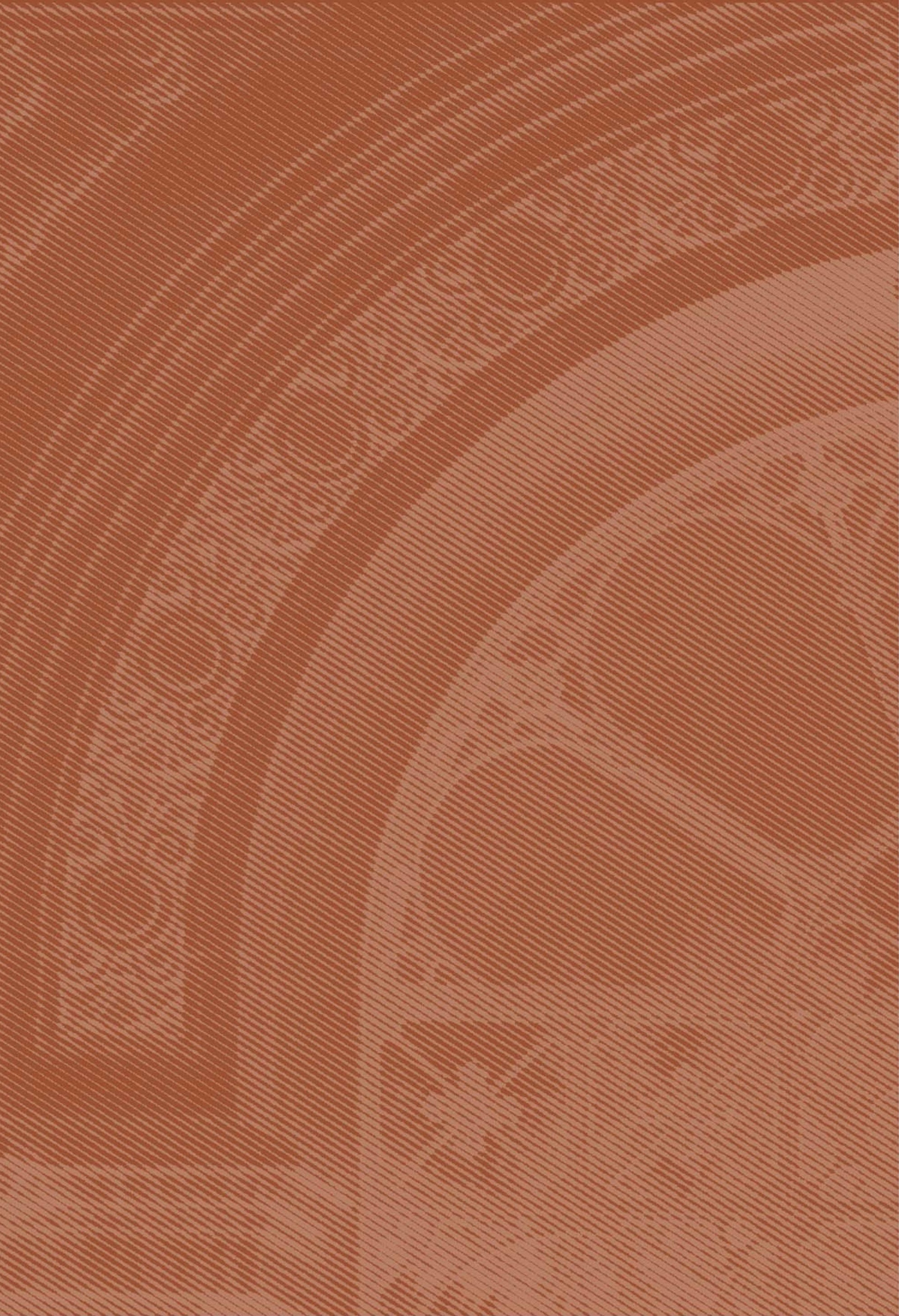

